\title{
Surface Topographic Analyses Two-Year Coupons of Alloy 22 from Long-Term Corrosion Testing
}

\author{
P.J. Bedrossian
}

December 16, 1999

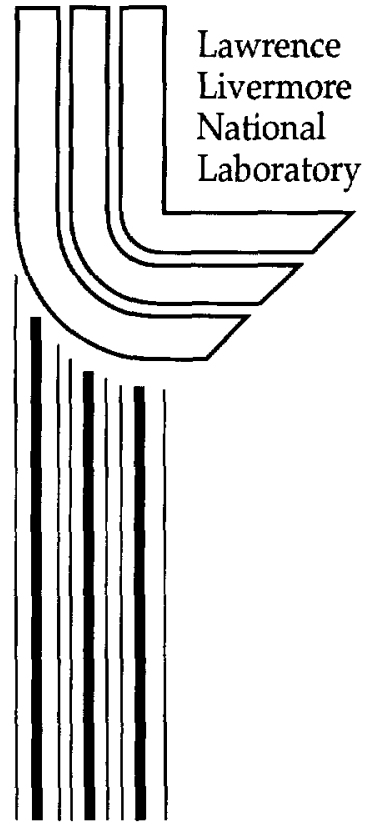




\section{DISCLAIMER}

This document was prepared as an account of work sponsored by an agency of the United States Government. Neither the United States Government nor the University of California nor any of their employees, makes any warranty, express or implied, or assumes any legal liability or responsibility for the accuracy, completeness, or usefulness of any information, apparatus, product, or process disclosed, or represents that its use would not infringe privately owned rights. Reference herein to any specific commercial product, process, or service by trade name, trademark, manufacturer, or otherwise, does not necessarily constitute or imply its endorsement, recommendation, or favoring by the United States Government or the University of California. The views and opinions of authors expressed herein do not necessarily state or reflect those of the United States Government or the University of California, and shall not be used for advertising or product endorsement purposes.

This work was performed under the auspices of the U. S. Department of Energy by the University of California, Lawrence Livermore National Laboratory under Contract No. W-7405-Eng-48.

This report has been reproduced directly from the best available copy.

Available electronically at http://www.doc.gov/bridge

Available for a processing fee to U.S. Department of Energy

And its contractors in paper from

U.S. Department of Energy

Office of Scientific and Technical Information

P.O. Box 62

Oak Ridge, TN 37831-0062

Telephone: (865) 576-8401

Facsimile: (865) 576-5728

E-mail: reports@adonis.osti.gov

Available for the sale to the public from

U.S. Department of Commerce

National Technical Information Service

5285 Port Royal Road

Springfield, VA 22161

Telephone: (800) 553-6847

Facsimile: (703) 605-6900

E-mail: orders@ntis.fedworld.gov

Online ordering: http://www.ntis.gov/ordering.htm

OR

Lawrence Livermore National Laboratory

Technical Information Department's Digital Library

http://www.llnl.gov/tid/Library.html 


\title{
Surface Topographic Analyses
}

of

Two-Year Coupons of Alloy 22

from

Long-Term Corrosion Testing

\author{
Peter J. Bedrossian \\ Division of Materials Science and Technology \\ and \\ Yucca Mountain Site Characterization Program, \\ Lawrence Livermore National Laboratory, Livermore CA 94551
}

16 December 1999

\section{Introduction}

We have applied atomic force microscopy (AFM) to analyze the surface topographies associated with representatives of each of the classes of aqueous-baths from which coupons of Alloy 22 were exposed for two years in Long-Term Corrosion Testing. The data support the conclusion that the AFM offers little, if any qualitative information on the corrosion of coupons which are currently undergoing Long-Term Testing.

\section{Methods}

Coupons of Alloy 22 immersed for two years in 60C and 90C SAW, SDW, and SCW electrolytes were analyzed with an atomic force microscope (AFM), according to the procedures in reference [1]. References to the details of long-term testing and the alloy and water compositions can also be found in that reference. below.

Selected, representative images of each class of coupons are shown in the figures

\section{Results}

All of the coupons tested, as well as a control coupon, showed roughness associated with localized depressions approaching the maximum, practical scan range of the AFM. Therefore, it is impossible to determine whether localized corrosion has occurred. The

\footnotetext{
' P. Bedrossian, "Surface Topographies of One-Year Weight-Loss Coupons of Alloy C22 from Long-Term Corrosion Testing." UCRL-ID-134649 (1999) 35 pages.
} 
following observations suggest that AFM does not offer a viable means of analyzing coupons which are currently undergoing Long-Term Testing.

1. The roughness associated with the machining of the surfaces is already a substantial proportion of the maximum, vertical scan range of the AFM and would obscure any indications of early stages of localized corrosion.

2. We have found from studying multiple, unexposed control coupons that there is substantial sample-to-sample variation in the overall roughness and the prevalence of deep depressions on as-received coupons. This variation associated with as-received surfaces obscures the difference between samples removed from testing and between the tested samples and the unexposed controls.

3. The images shown below represent only those regions which were smooth enough to scan. The Scientific Notebook documents numerous cases in which regions of control coupons as well as coupons removed from Long-Term testing were too rough to scan at all. Therefore, the coupons currently undergoing testing already exceed the vertical range of the AFM.

4. Because both exposed and unexposed (control) coupons show deep depressions which approach the practical, vertical range of the AFM, further growth of the depressions would quickly take those features beyond the vertical range the instrument. Therefore, the AFM would be unsuitable for studying subsequent evolution of the surface topographies of the coupons currently undergoing LongTerm Testing.

\section{Summary}

The high corrosion resistance of Alloy 22 forces a credible study of localized corrosion to nanometer length scales. Therefore, it is necessary to test well-defined and consistent surfaces. The roughness of the starting surface places a lower bound on the dimensions of observable topographic evolution which might be associated with corrosion. Therefore, further work on the microscopic level should emphasize the use of metallographically-polished coupons.

\section{Acknowledgments}

The author is grateful to David Fix for assistance with AFM measurements. The work was performed at Lawrence Livermore National Laboratory under the auspices of the US-DOE under contract W-7504-Eng-48, and was supported by the Yucca Mountain Site Characterization Program. 


\section{Table of Figures}

Figure 1: Obverse side of coupon DCA_046, exposed to 90C SAW for 2 years, outside crevice. (file 991104a.011).

Figure 2: Detail of the central region of Figure 1: Obverse side of coupon DCA_046, exposed to 90C SAW for 2 years, outside crevice. (file 991104a.012).

Figure 3: Profile of the depression appearing in the center of Figure 2: Detail of the central region of Figure 1: Obverse side of coupon DCA_046, exposed to 90C SAW for 2 years, outside crevice.

Figure 4: Obverse side of DCA172, exposed to 90C SDW for two years, inside crevice.

(file 991109a.001)

Figure 5: Detail of lower left region of Figure 4. (file 991108a.002) ...........................9

Figure 6: Profile of the depression appearing in the central region of Figure 5............ 10

Figure 7: Obverse side of DCA172, exposed to 90C SDW for two years, inside crevice.

(file 991108a.005)

Figure 8: Detailed image of the central region of Figure 7. (file 991108a.006) ............ 12

Figure 9: Profile of the depression appearing in the central region of Figure 8............. 13

Figure 10: Obverse side of DCA172, exposed to 90C SDW for two years, outside

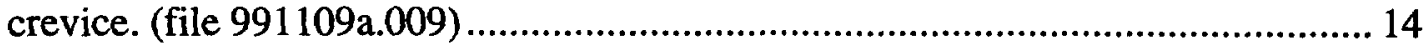

Figure 11: Detail of the depression in the lower portion of Figure 10. (file 991108a.010)

Figure 12: Profile of the prominent depression appearing in Figure 11..................... 16

Figure 13: Obverse side of DCA172, exposed to 90C SDW for two years, outside crevice. (file 991108a.011) .......................................................................... 17

Figure 14: Detail of the prominent depression in Figure 13. (file 991108a.012)........... 18

Figure 15: Obverse side of DWA126, exposed to 90C SCW for two years. This was a weight loss coupon; no crevice coupon in this category was available. (file 991118a.001)

Figure 16: Detail of the central region of Figure 15. (file 991118a.002)...................... 20

Figure 17: Profile of the depression in the center-right region of Figure 16.................. 21

Figure 18: Obverse side of DCA016, exposed to 60C SAW for two years, inside crevice.

(file 991119a.003)

Figure 19: Obverse side of DCA016, exposed to 60C SAW for two years, outside crevice. (file 991119a.005).

Figure 20: Detail of the prominent depression appearing in Figure 19. (file 991119a.006).

Figure 21: Obverse side of DCA076, exposed to 60C SCW for two years, inside crevice.

(file 991122a.001)

Figure 22: Detail of the lower right region of Figure 21. (file 991122a.002) .............. 26

Figure 23: Profile of the depression appearing in the left center region of Figure $22 \ldots . .27$

Figure 24: Obverse side of DCA076, exposed to 60C SCW for two years, inside crevice.

(file 991122a.003)

Figure 25: Detail of the depression appearing in the upper left region of Figure 24. (file 991122a.004)

Figure 26: Profile of the prominent depression appearing in Figure 25. 
Figure 27: Obverse side of DCA076, exposed to 60C SCW for two years, outside crevice.

(file 991122a.007) 31

Figure 28: Obverse side of DCA136, exposed to 60C SDW for two years, inside crevice.

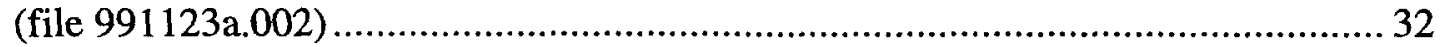

Figure 29: Detail of the left center region of Figure 28. (file 991123a.003)................ 33

Figure 30: Profile across the prominent depression appearing in Figure 29................. 34

Figure 31: Obverse side of DCA136, exposed to 60C SDW for two years, inside crevice.

(file 991123a.005) 35

Figure 32: Profile of the narrow depression appearing in the right central region of

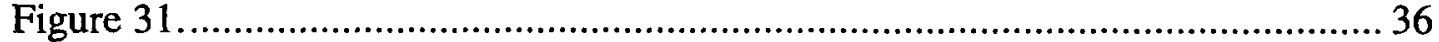

Figure 33: Obverse side of DCA136, exposed to 60C SDW for two years, outside

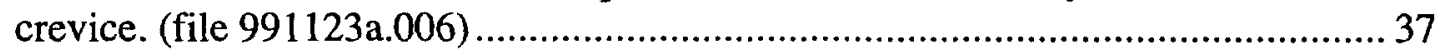

Figure 34: Detail of the lower left region of Figure 33. (file 991123a.007) ................. 38

Figure 35: Profile of the upper right depression in central region of Figure 34............. 39

Figure 36: Obverse side of DCA243, an unexposed, control, crevice coupon. (file

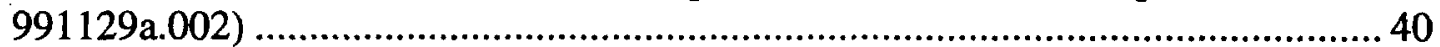

Figure 37: Profile of the prominent depression in the lower right of Figure 36............ 41

Figure 38: Obverse side of DCA243, an unexposed, control, crevice coupon. (file

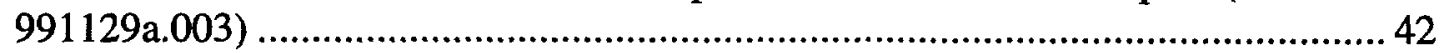

Figure 39: Profile of the depression in the lower portion of Figure 38. ...................... 43

Figure 40: Profile of the depression in the upper central region of Figure 38.............. 44 


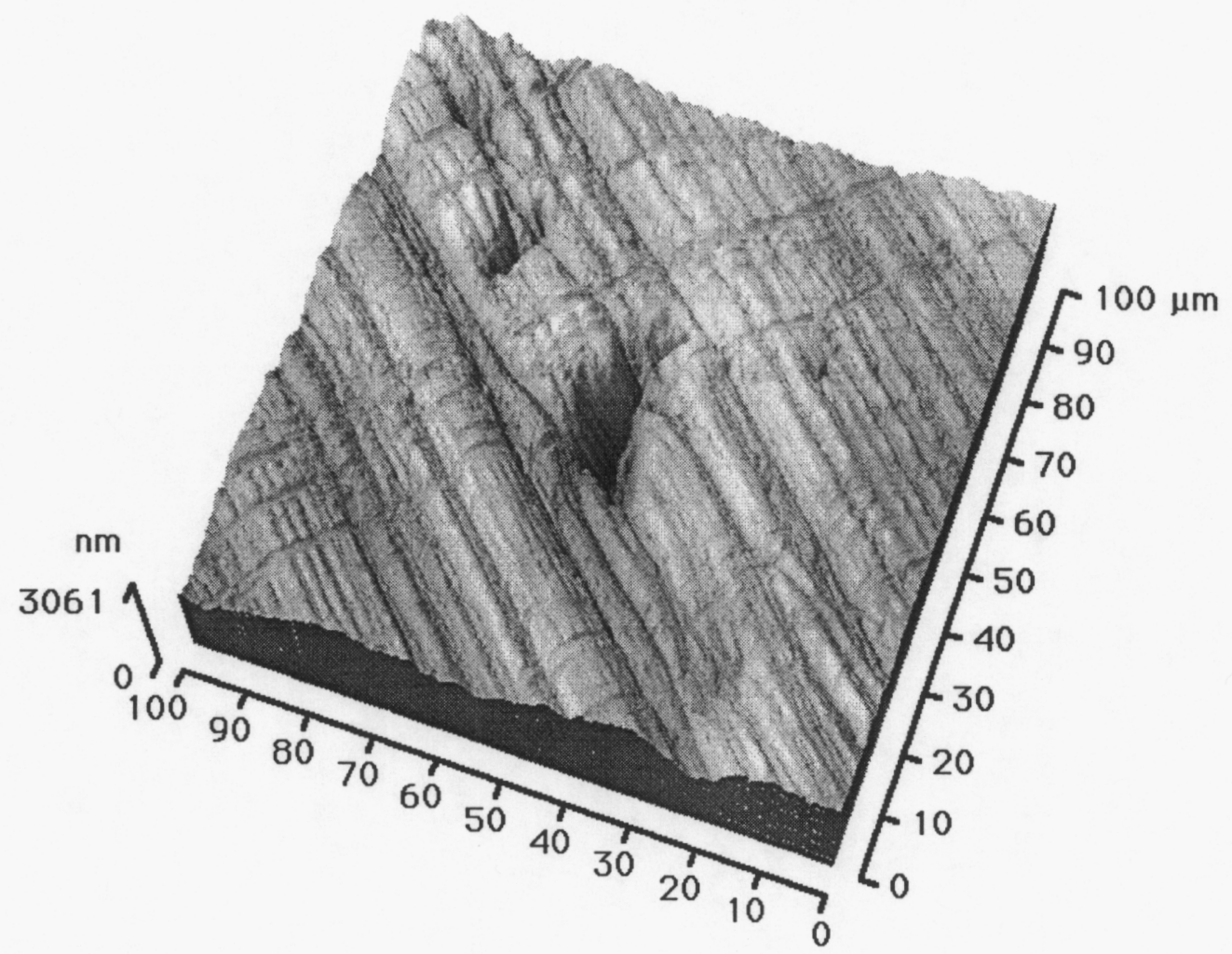

Figure 1: Obverse side of coupon DCA_046, exposed to 90C SAW for 2 years, outside crevice. (file 991104a.011) 


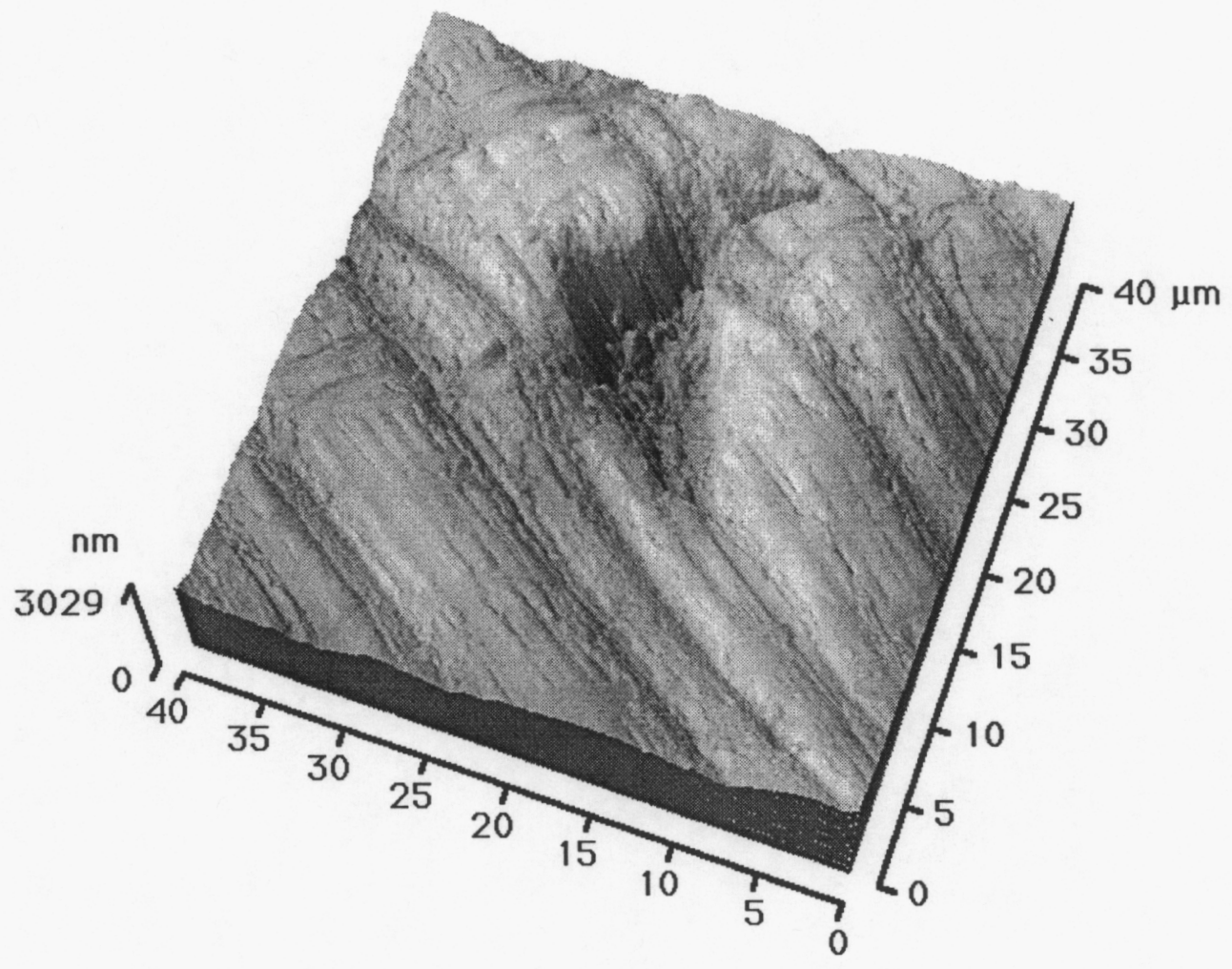

Figure 2: Detail of the central region of Figure 1: Obverse side of coupon DCA_046, exposed to 90C SAW for 2 years, outside crevice. (file 991104a.012) 


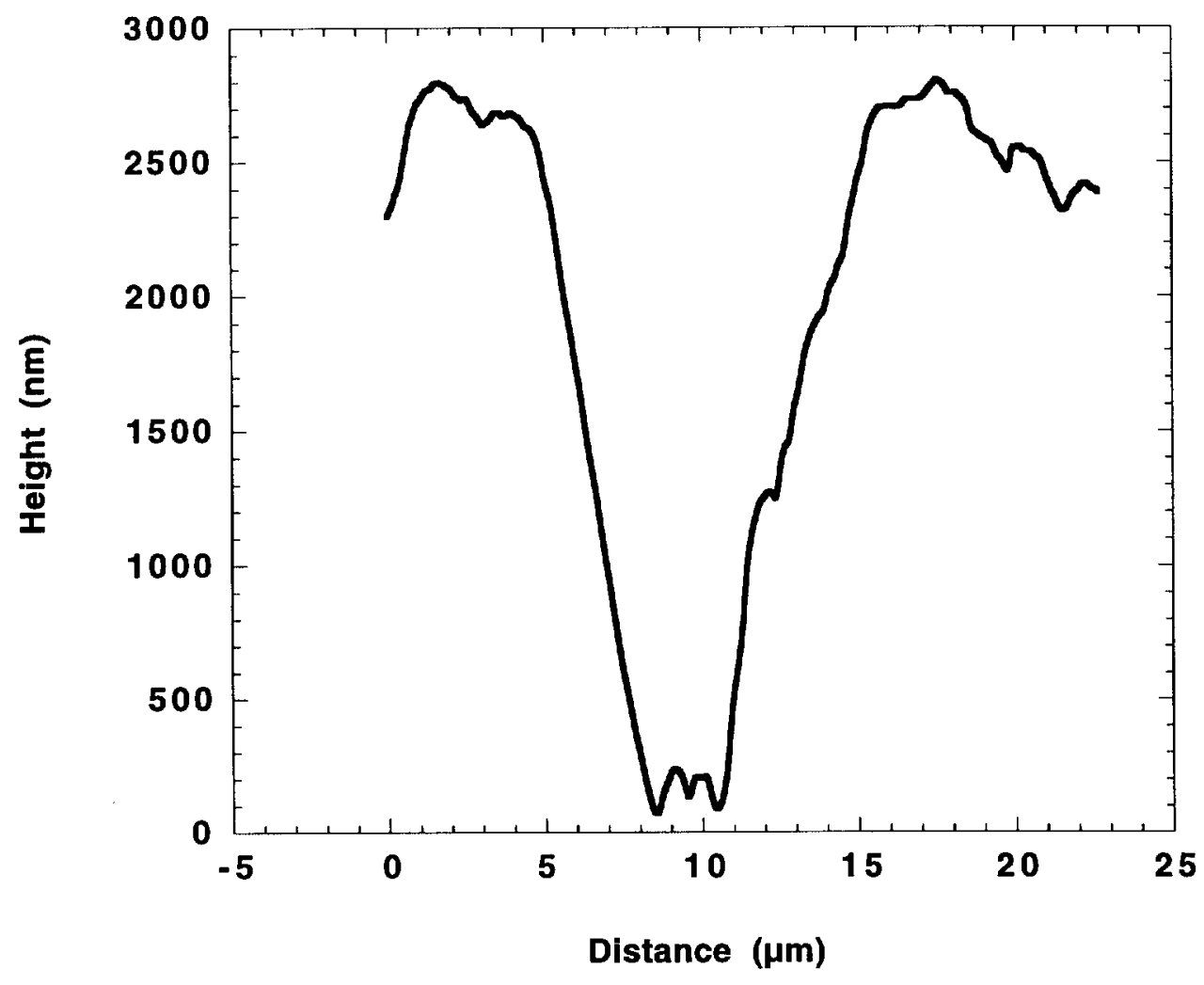

Figure 3: Profile of the depression appearing in the center of Figure 2: Detail of the central region of Figure 1: Obverse side of coupon DCA_046, exposed to 90C SAW for 2 years, outside crevice. 


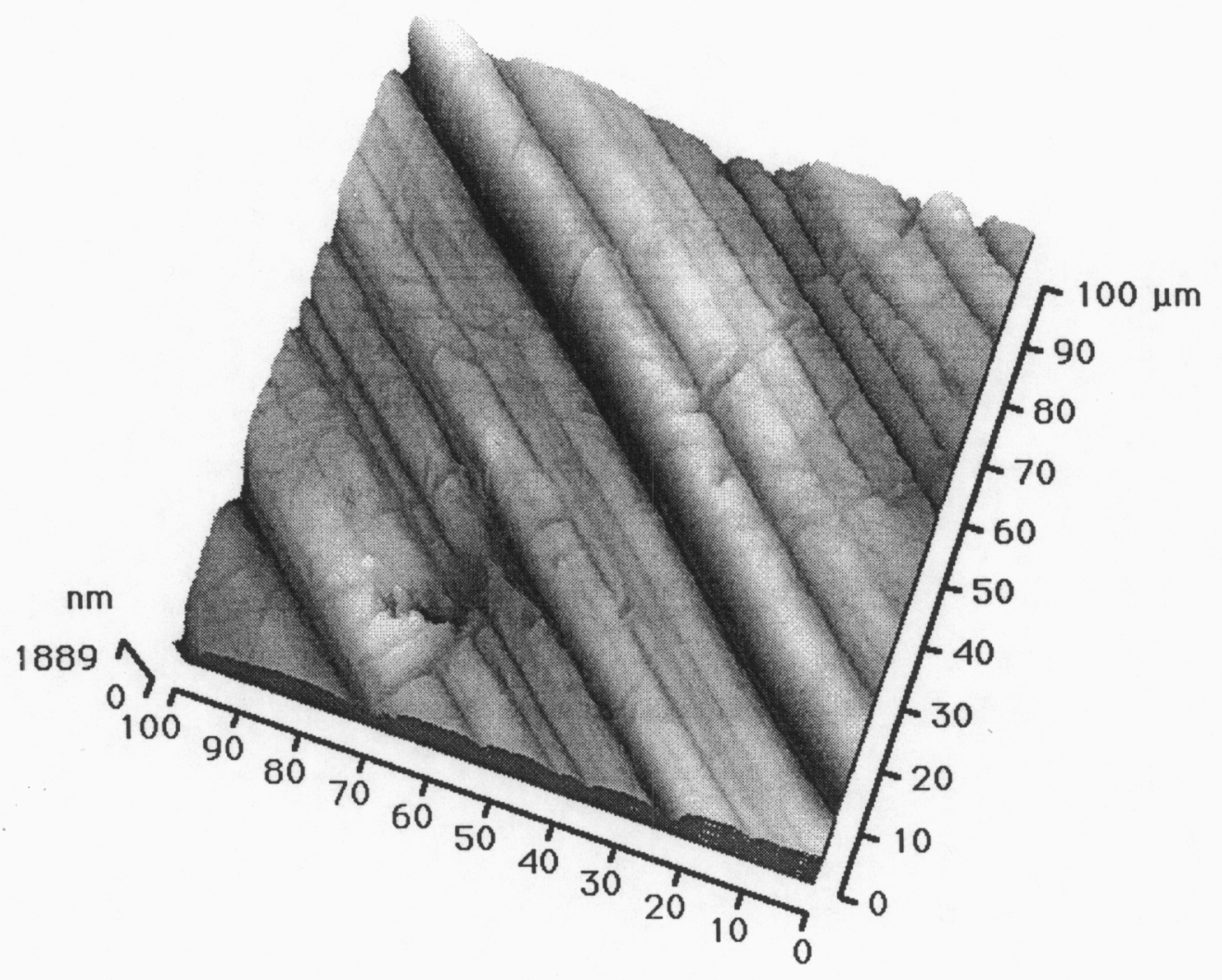

Figure 4: Obverse side of DCA172, exposed to 90C SDW for two years, inside crevice. (file 991109a.001) 


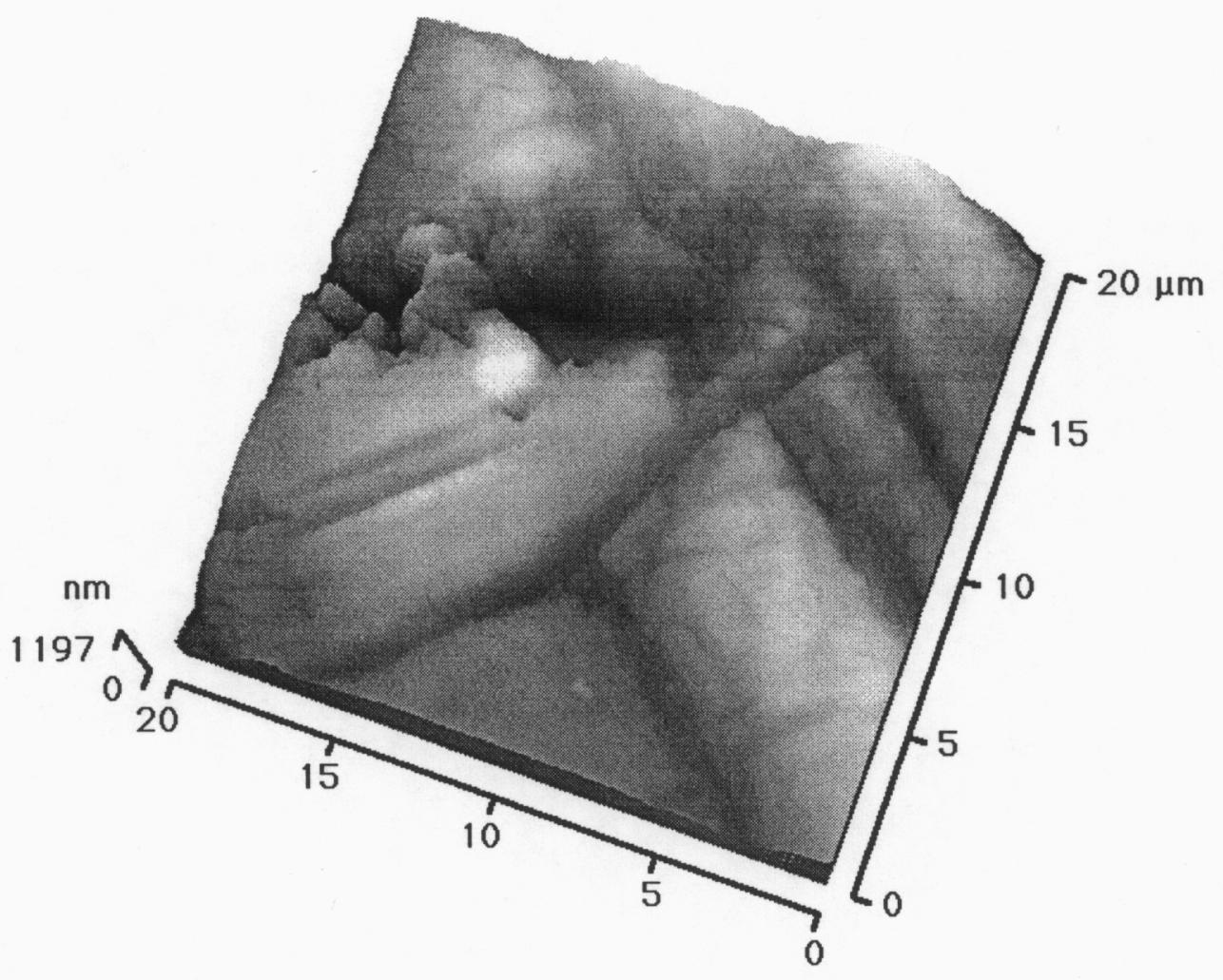

Figure 5: Detail of lower left region of Figure 4. (file 991108a.002) 


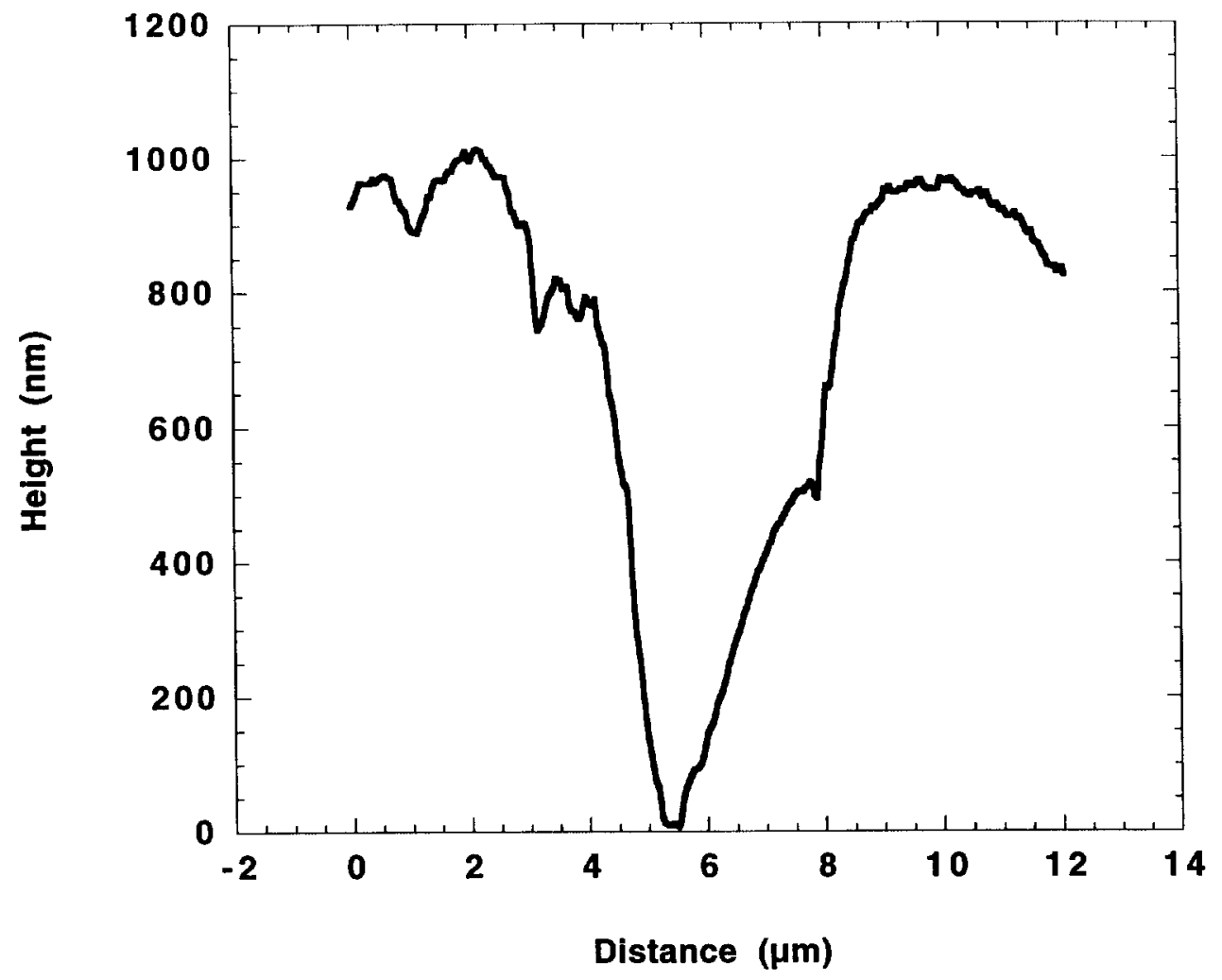

Figure 6: Profile of the depression appearing in the central region of Figure 5. 


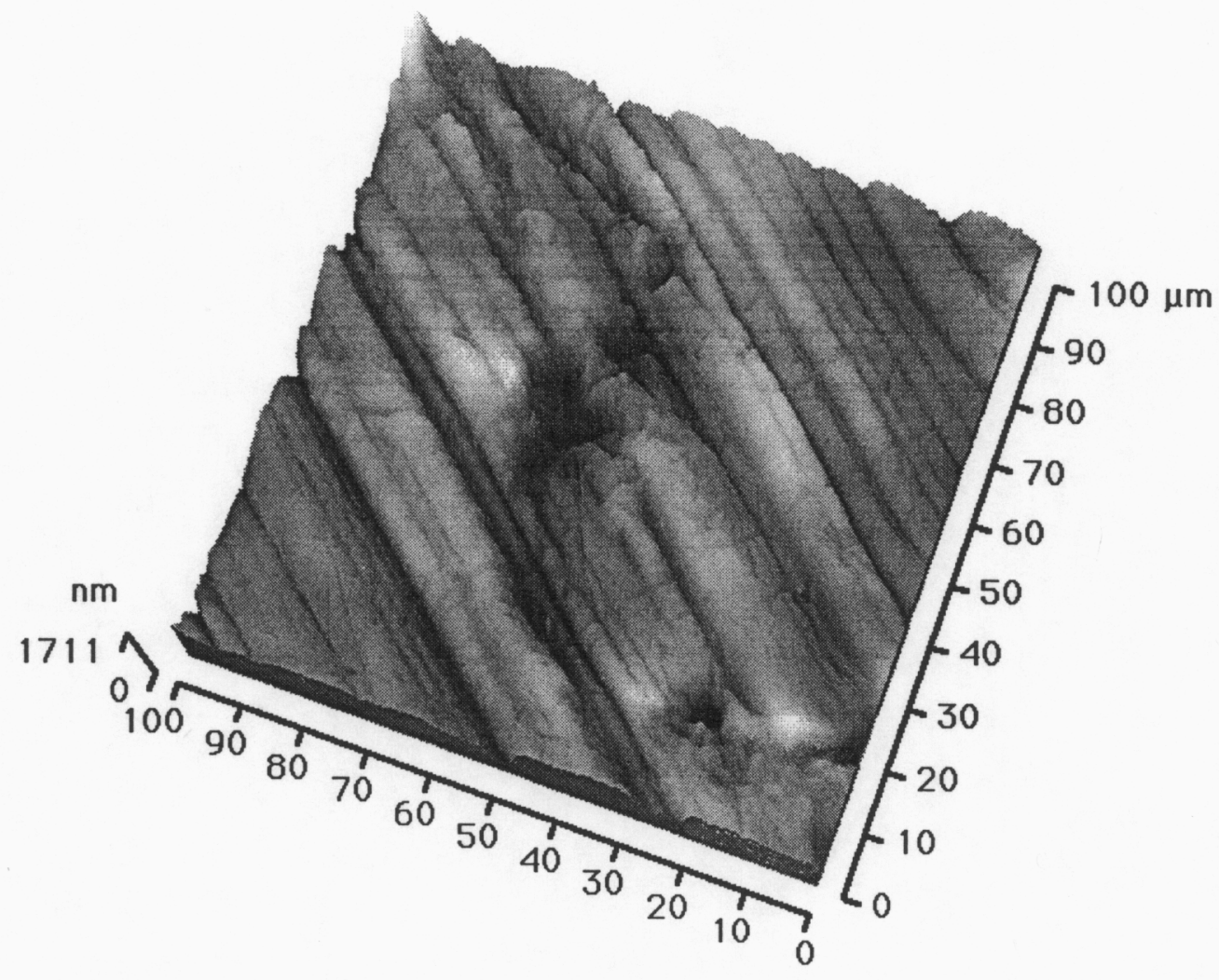

Figure 7: Obverse side of DCA172, exposed to 90C SDW for two years, inside crevice. (file 991108a.005) 


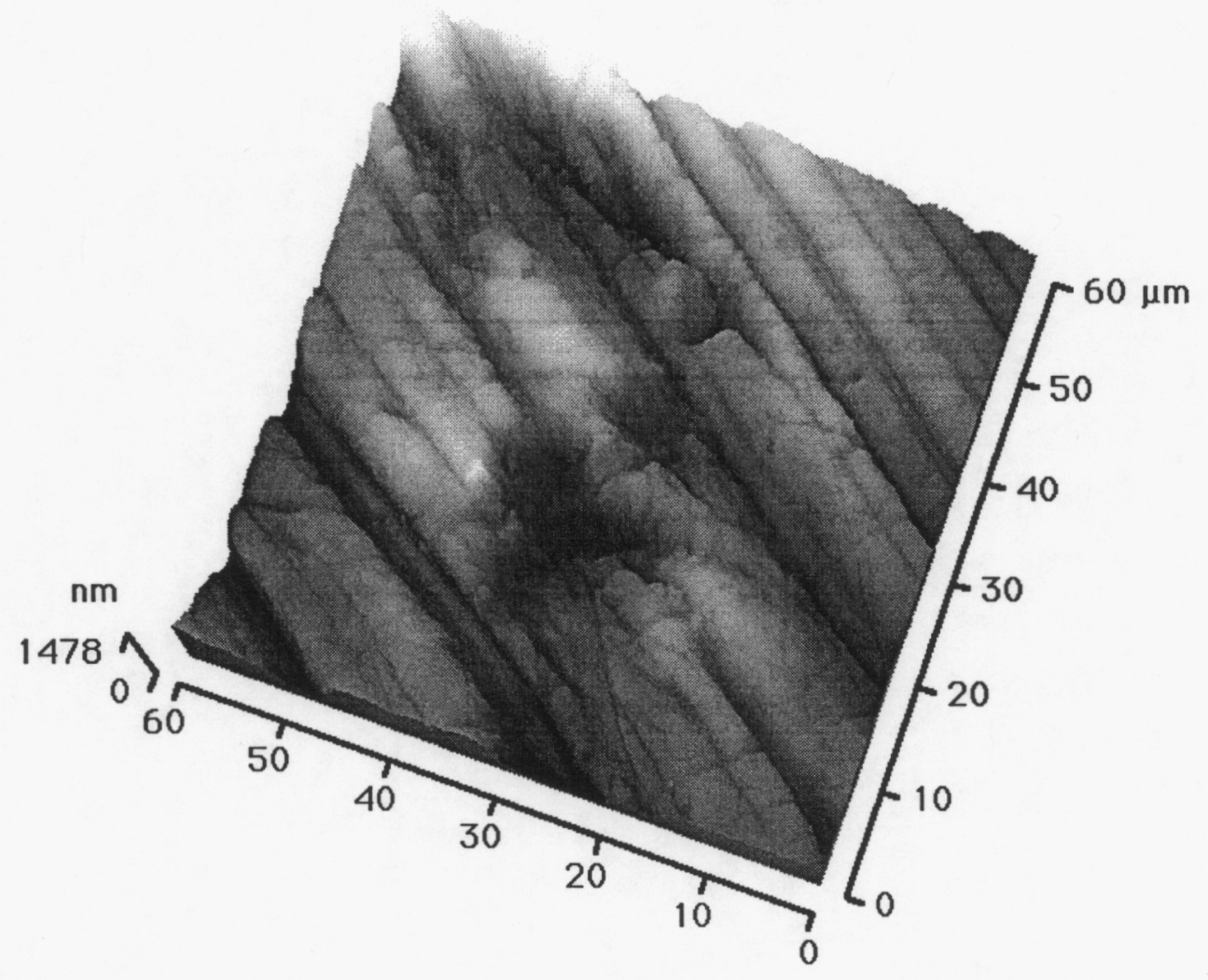

Figure 8: Detailed image of the central region of Figure 7. (file 991108a.006) 


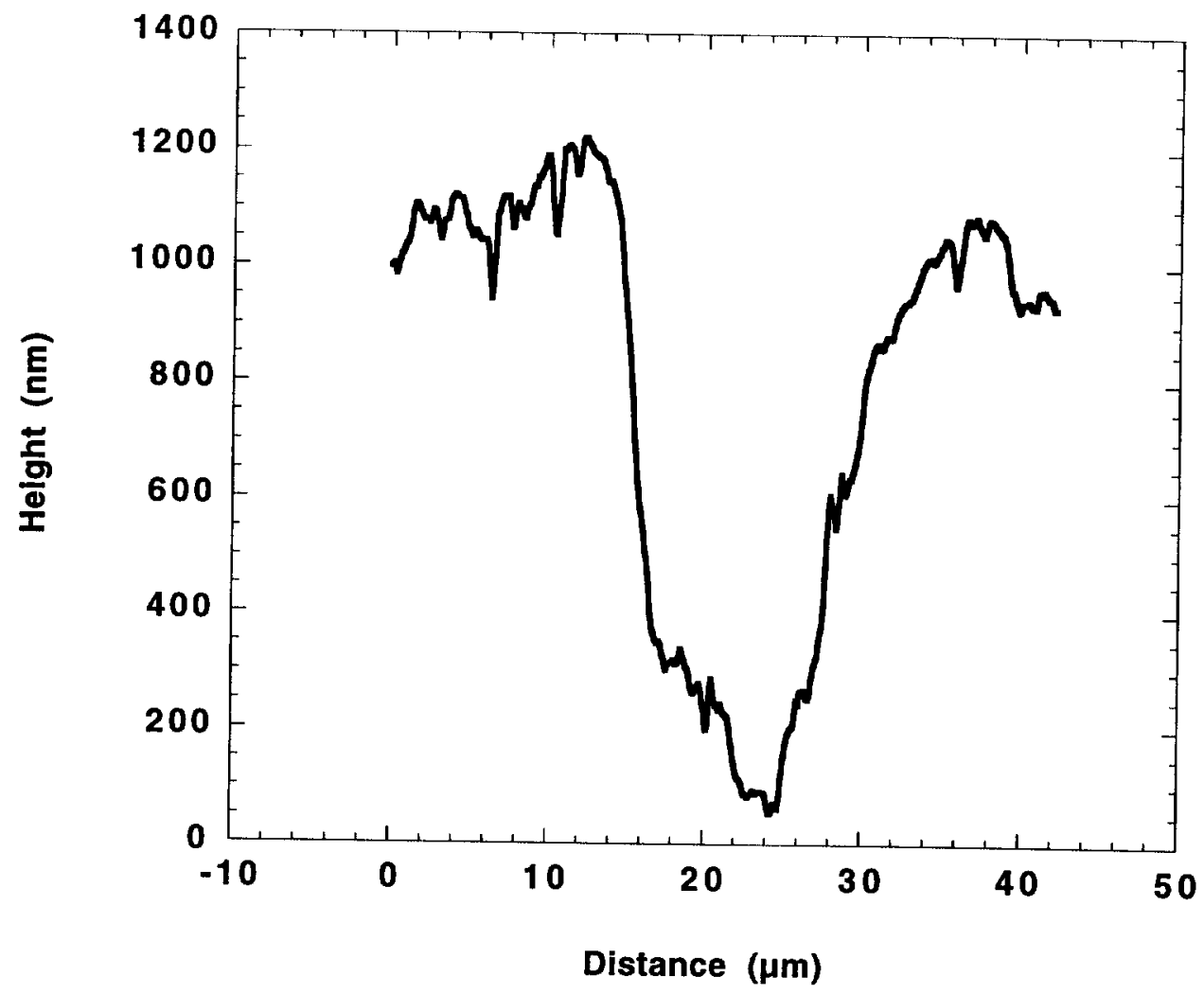

Figure 9: Profile of the depression appearing in the central region of Figure 8. 


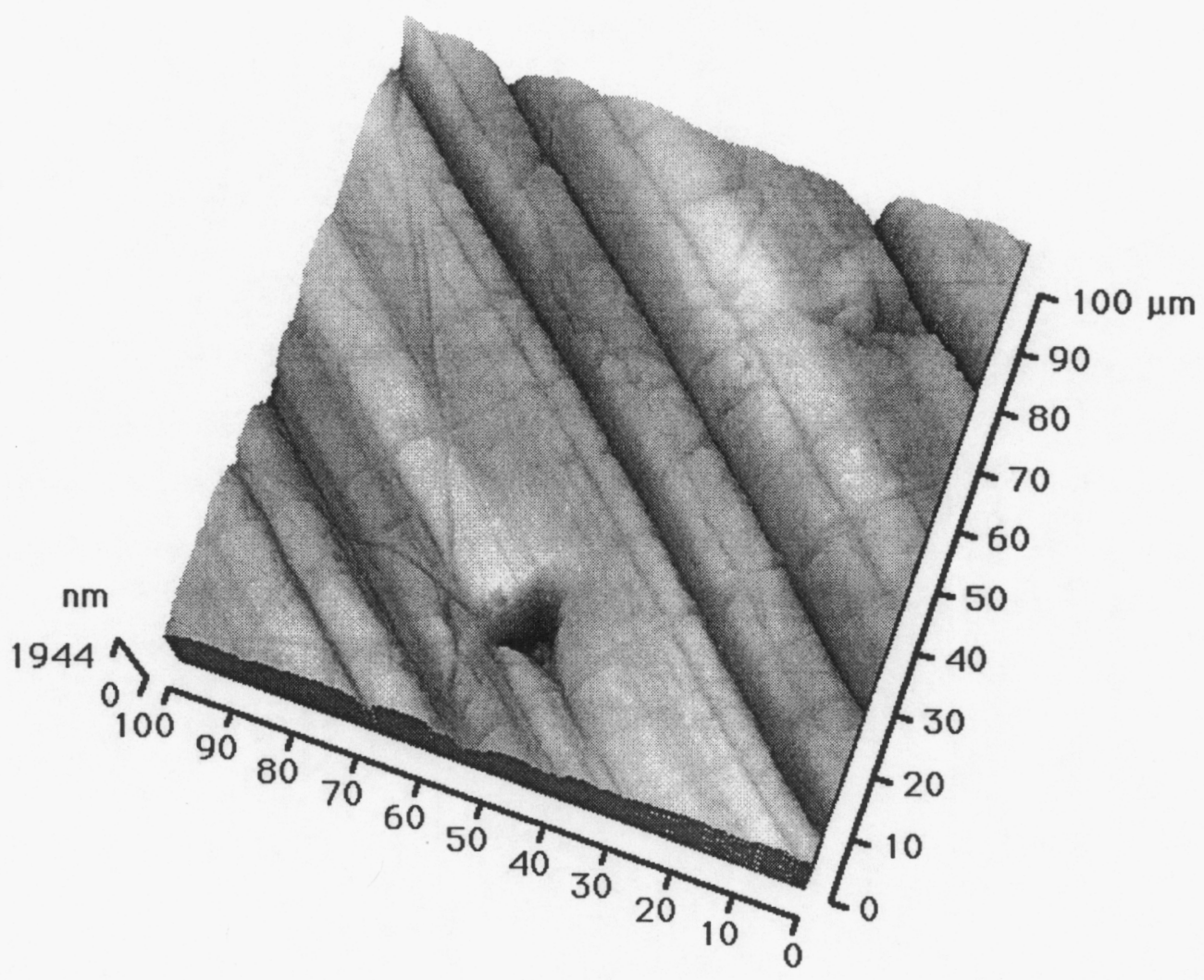

Figure 10: Obverse side of DCA172, exposed to 90C SDW for two years, outside crevice. (file 991109a.009) 


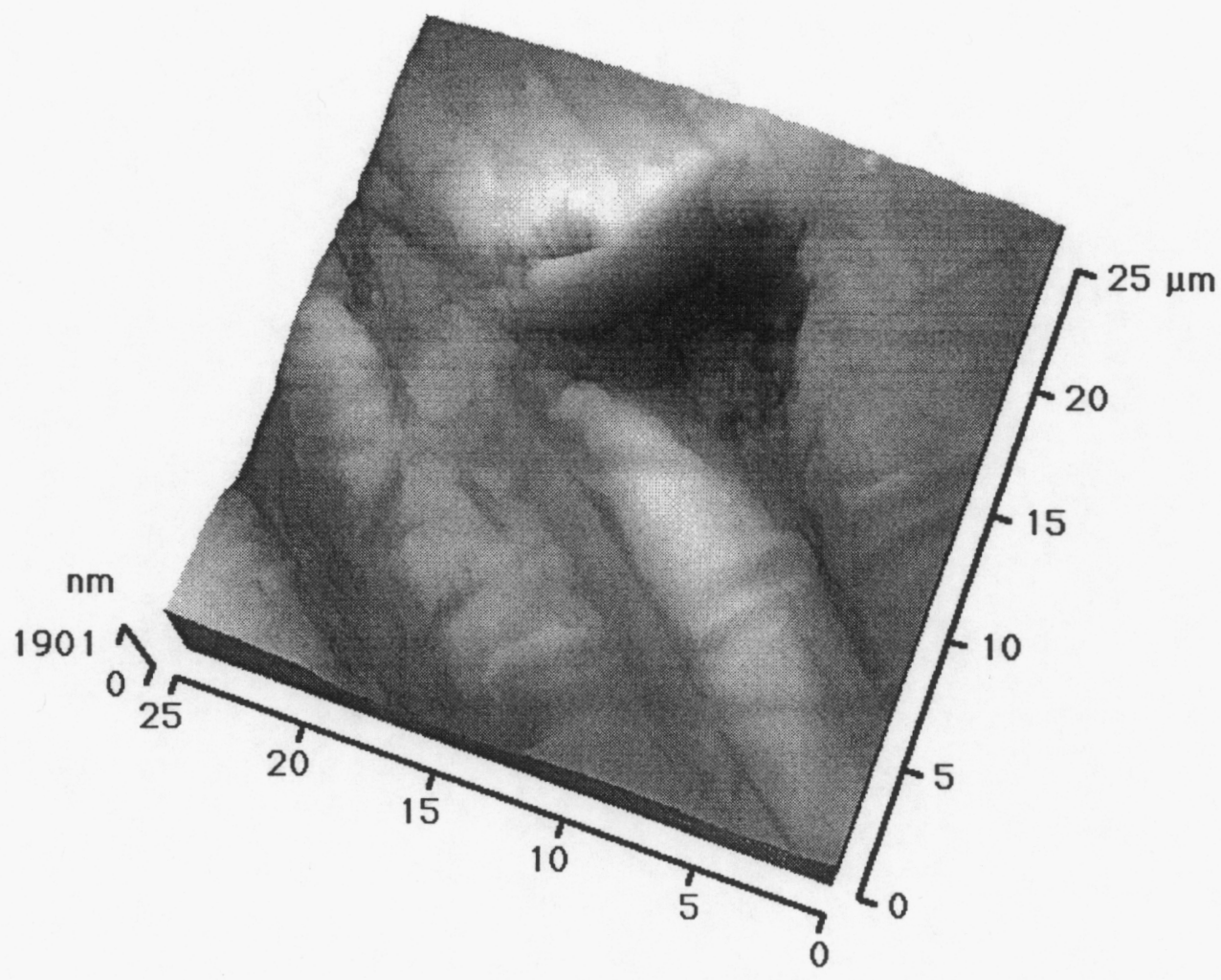

Figure 11: Detail of the depression in the lower portion of Figure 10. (file 991108a.010) 


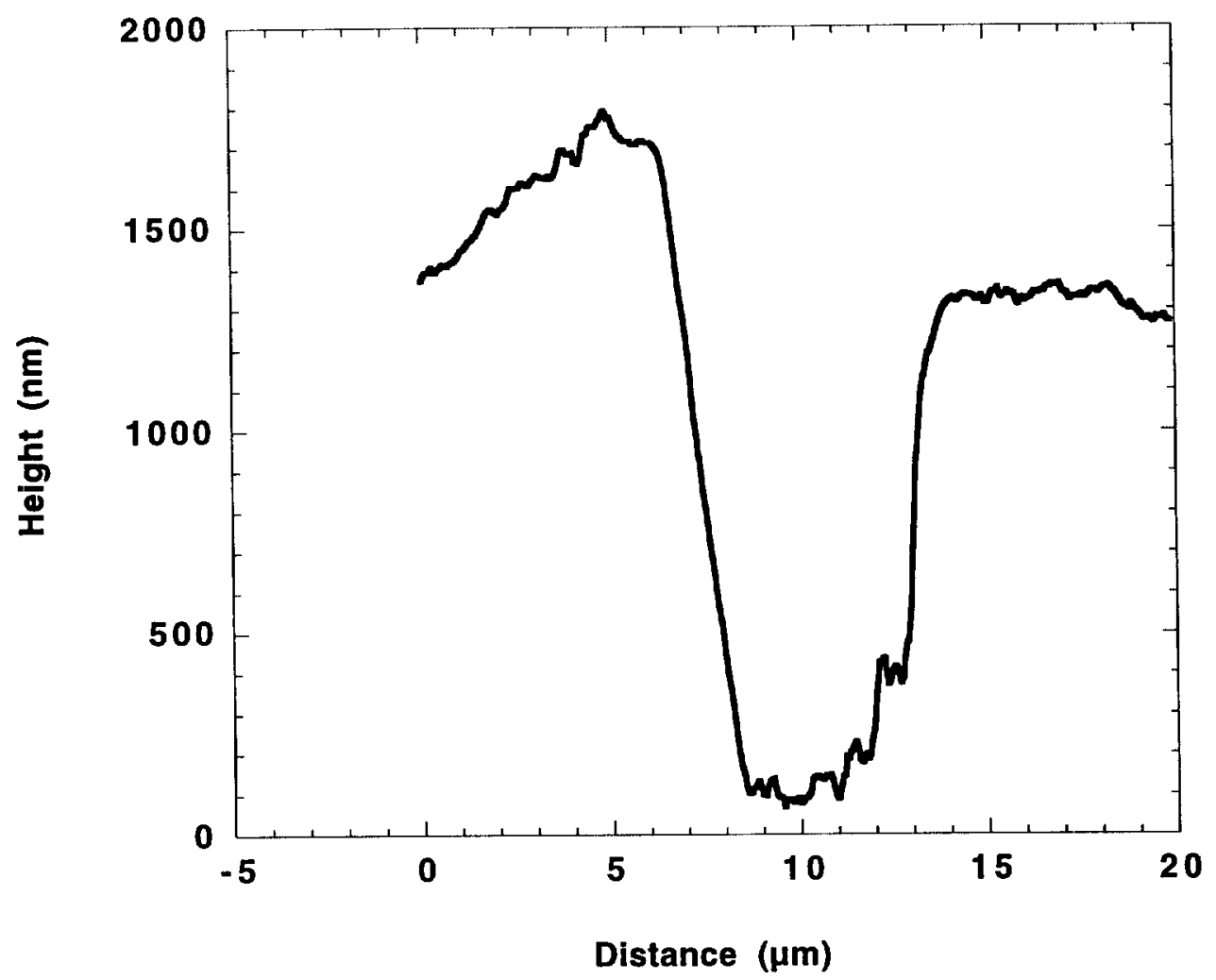

Figure 12: Profile of the prominent depression appearing in Figure 11. 


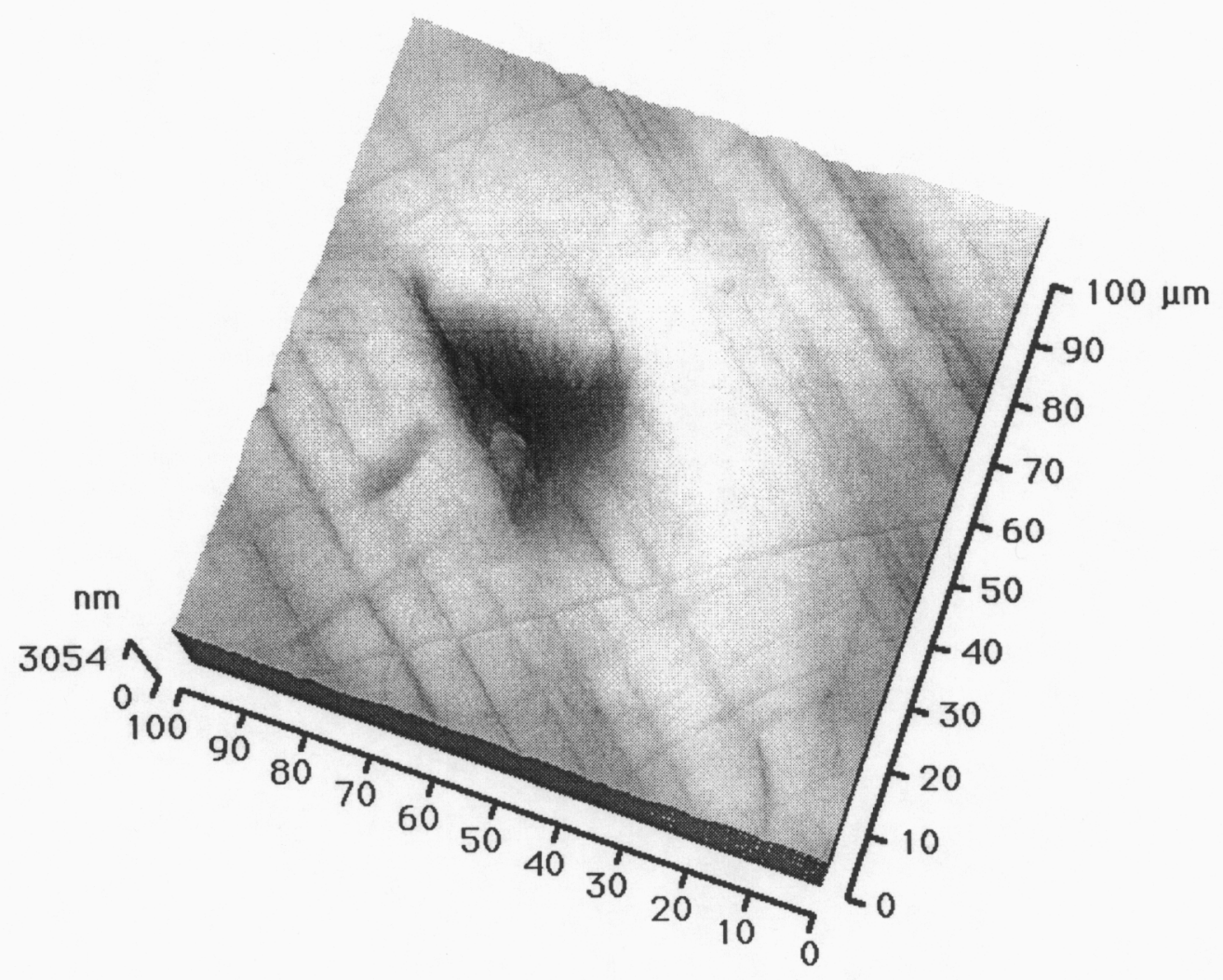

Figure 13: Obverse side of DCA172, exposed to 90C SDW for two years, outside crevice. (file 991108a.011). 


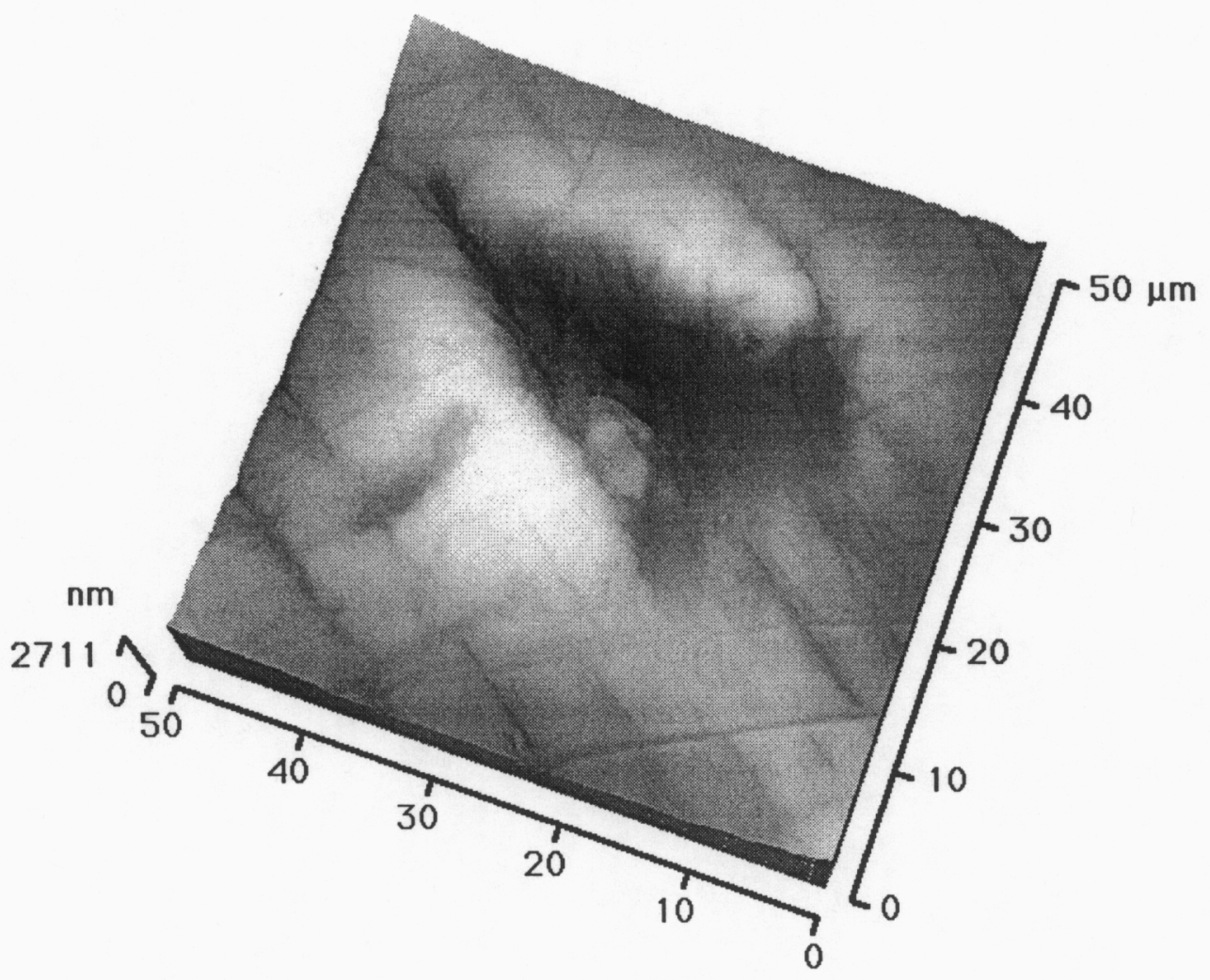

Figure 14: Detail of the prominent depression in Figure 13. (file 991108a.012) 


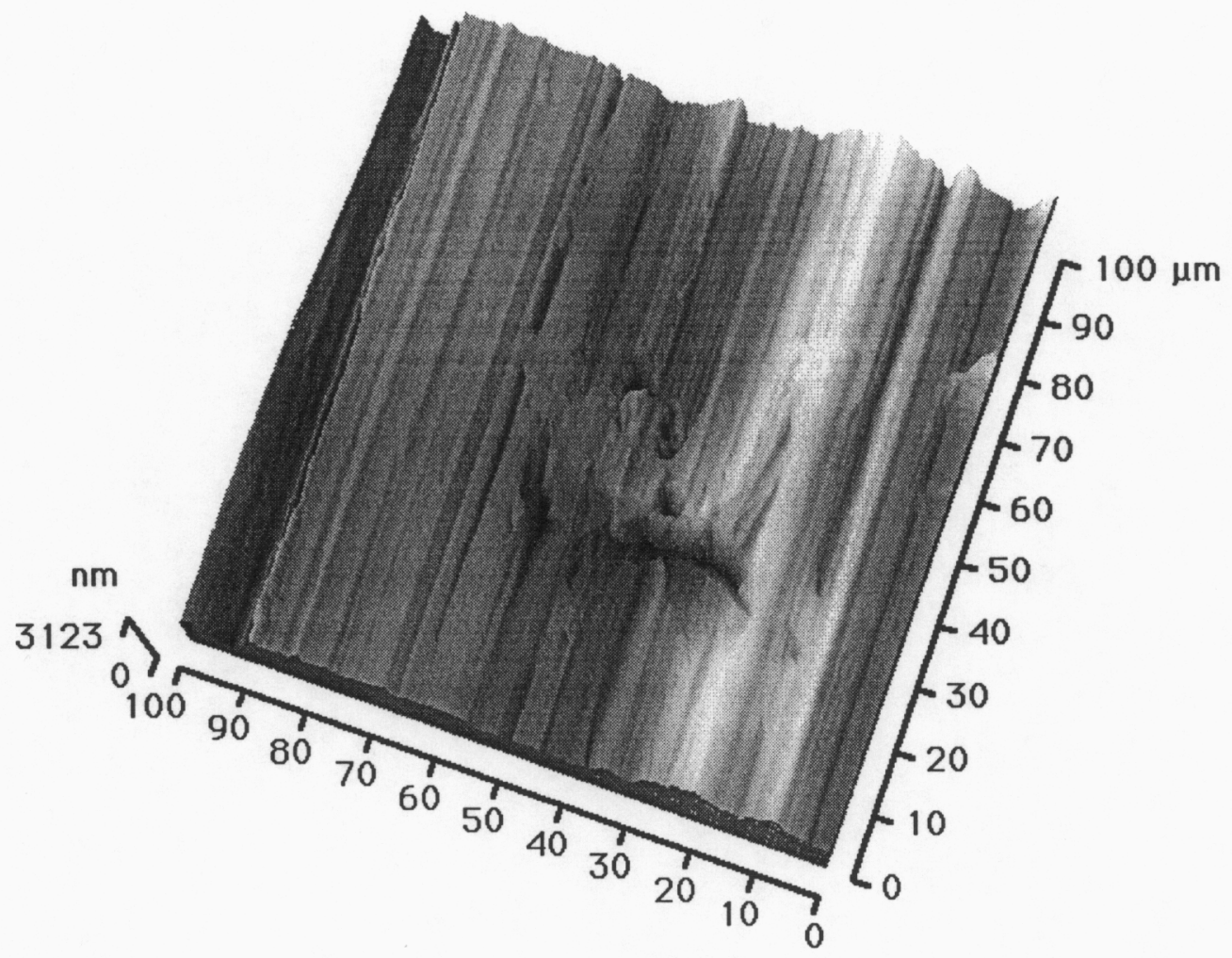

Figure 15: Obverse side of DWA126, exposed to $90 \mathrm{C} \mathrm{SCW}$ for two years. This was a weight loss coupon; no crevice coupon in this category was available. (file 991118a.001) 


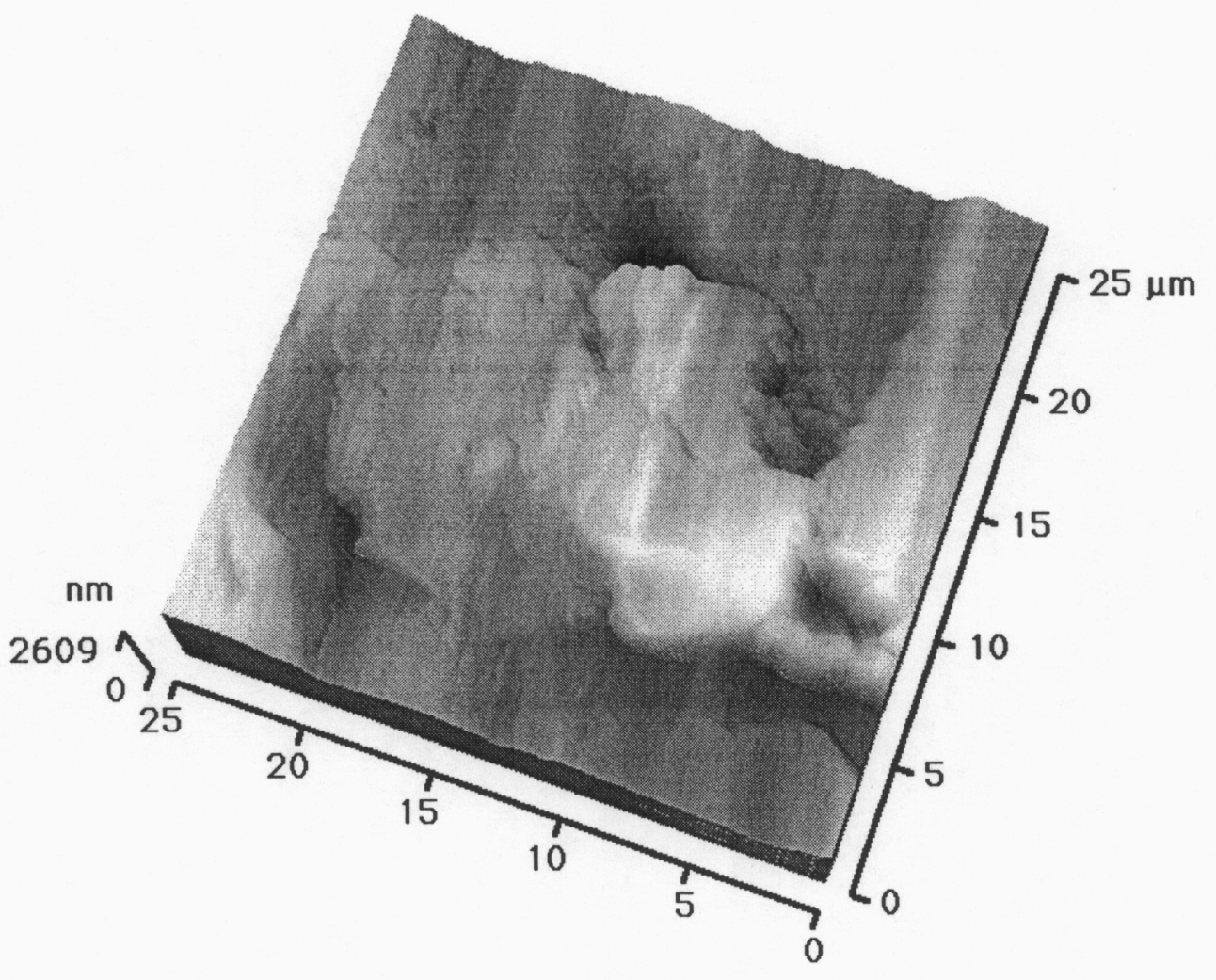

Figure 16: Detail of the central region of Figure 15. (file 991118a.002) 


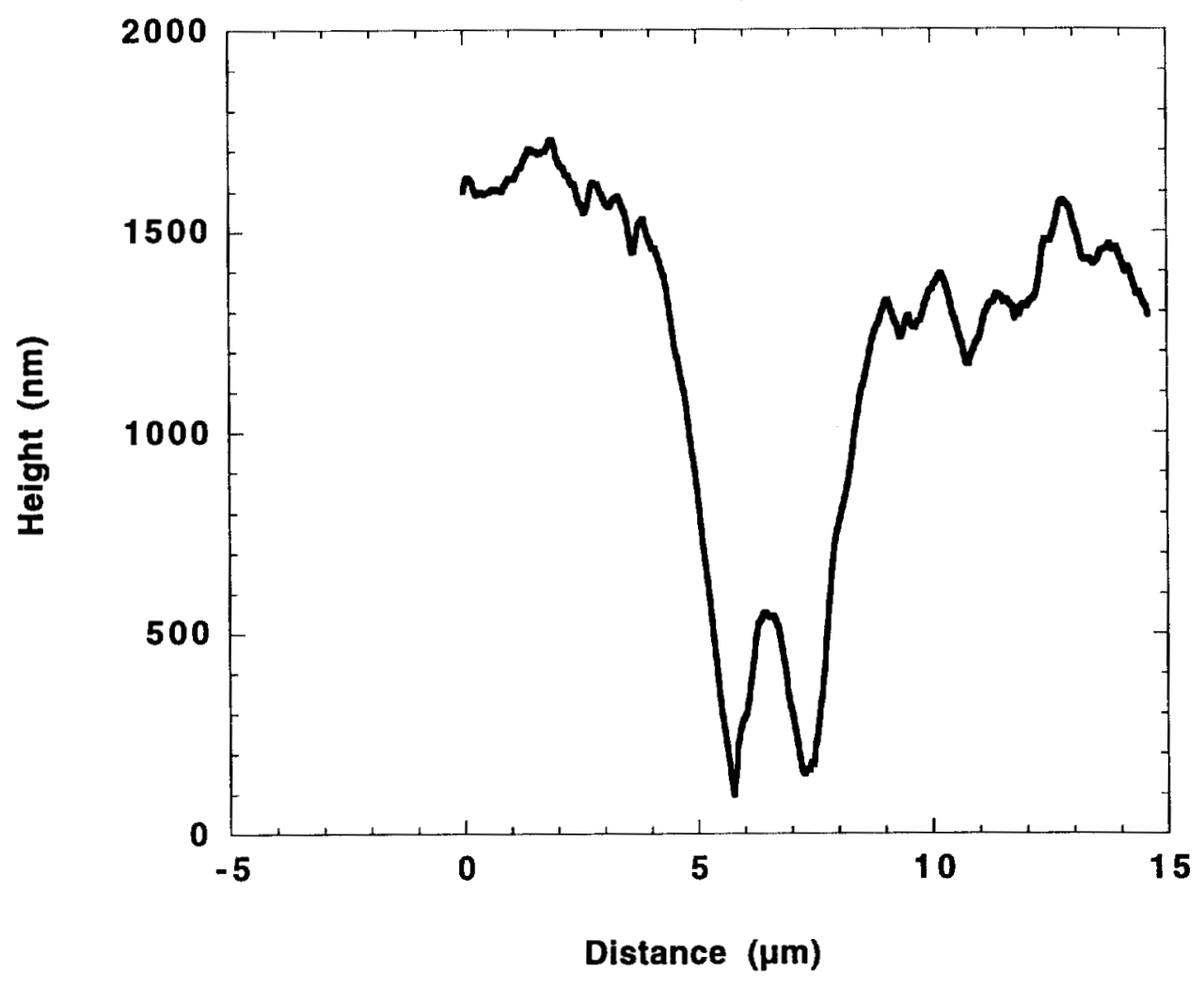

Figure 17: Profile of the depression in the center-right region of Figure 16. 


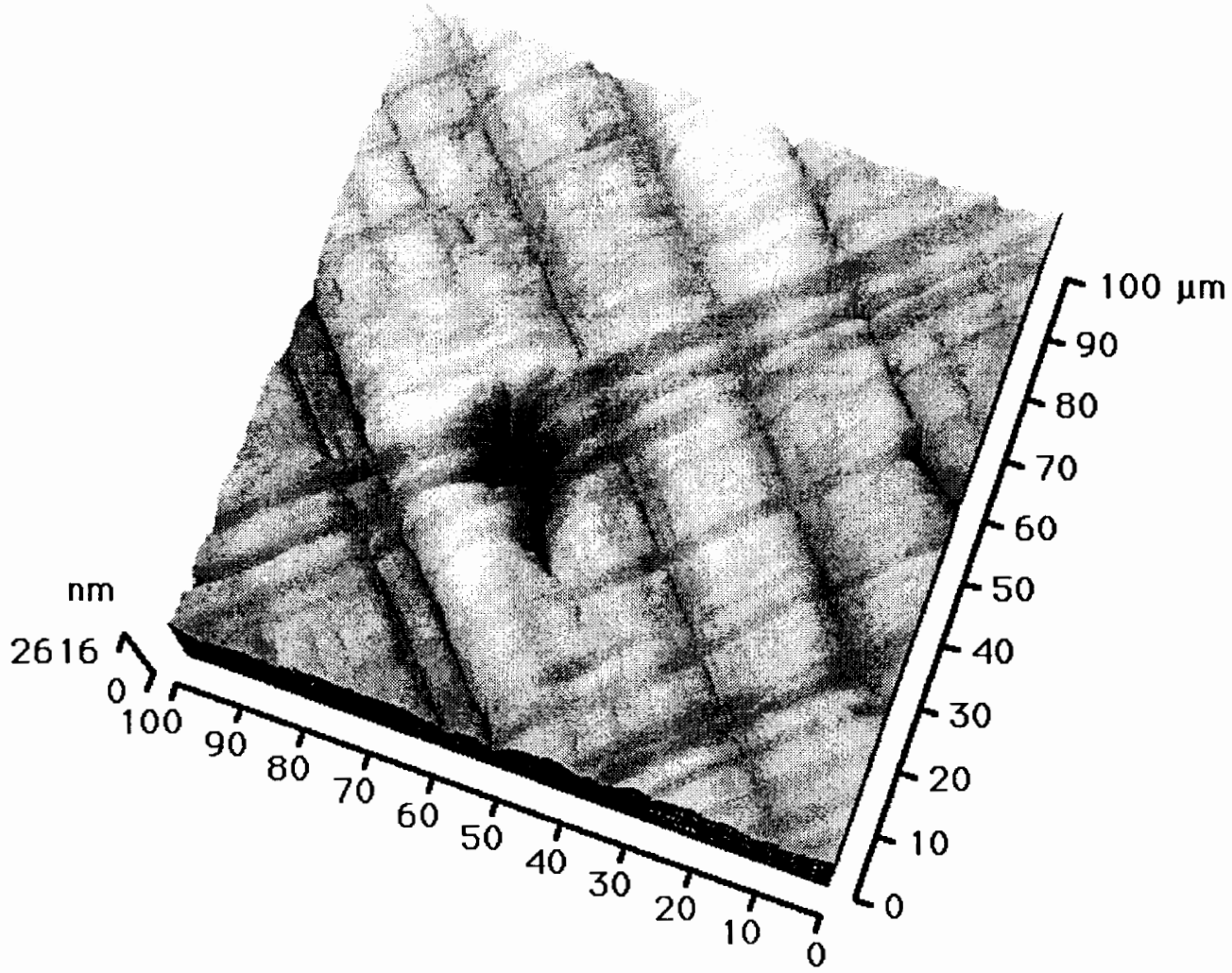

Figure 18: Obverse side of DCA016, exposed to 60C SAW for two years, inside crevice. (file 991119a.003) 


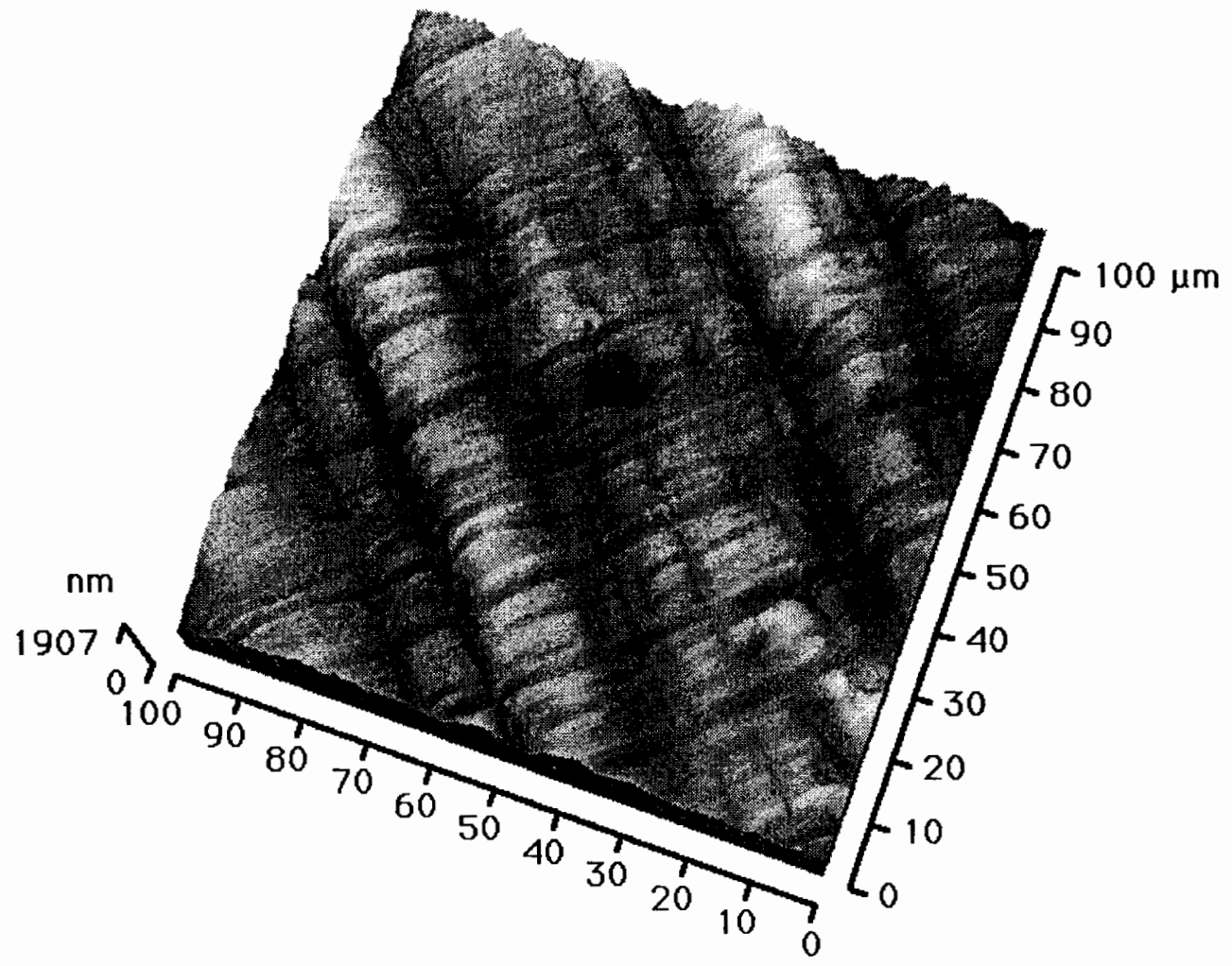

Figure 19: Obverse side of DCA016, exposed to 60C SAW for two years, outside crevice. (file 991119a.005) 


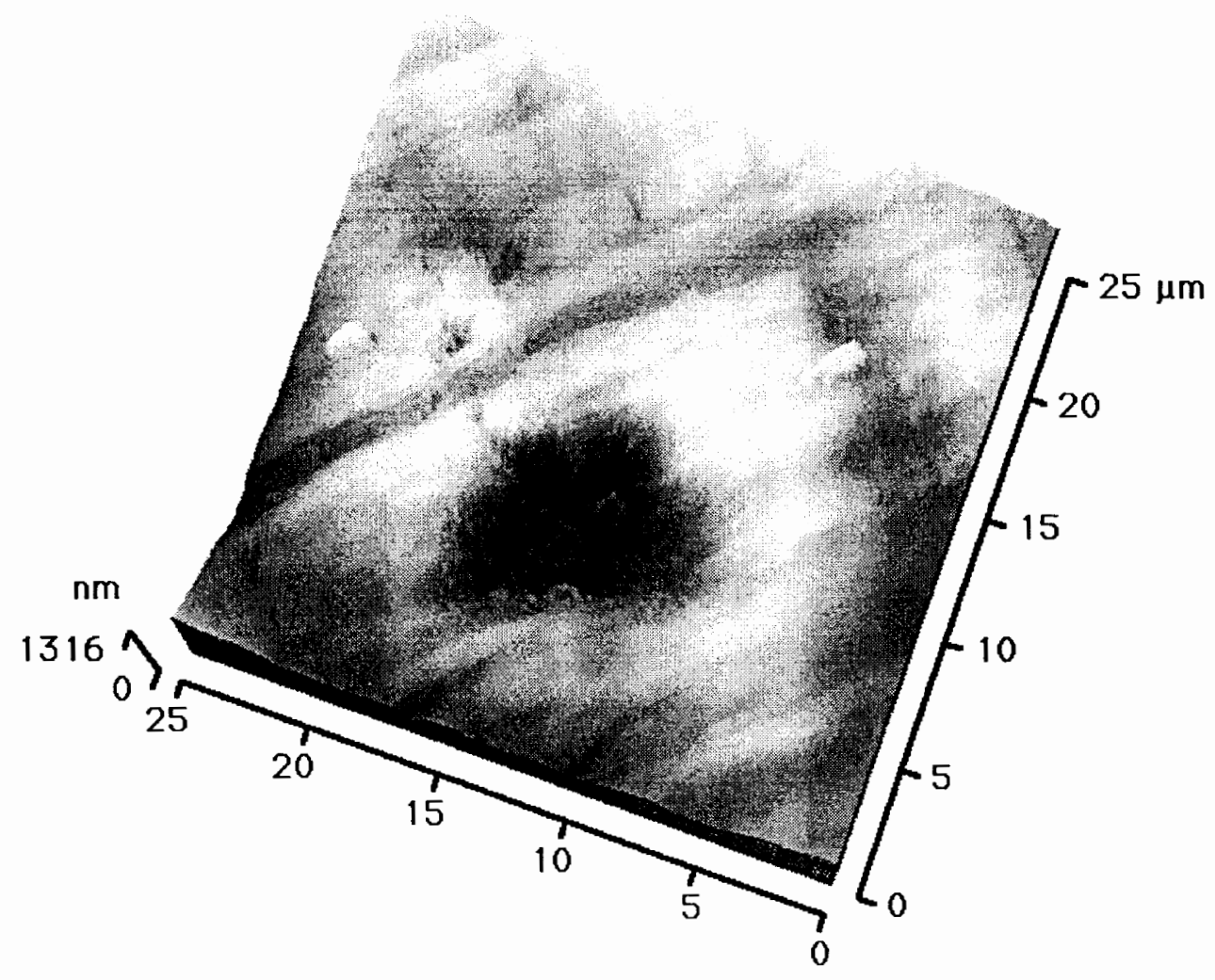

Figure 20: Detail of the prominent depression appearing in Figure 19. (file 991119a.006). 


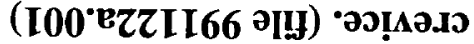

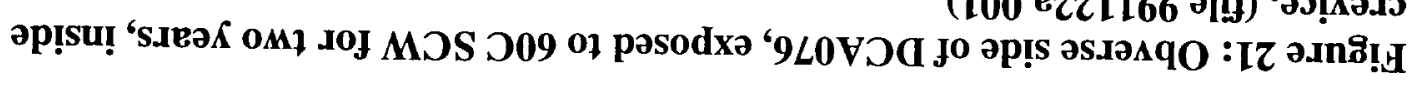

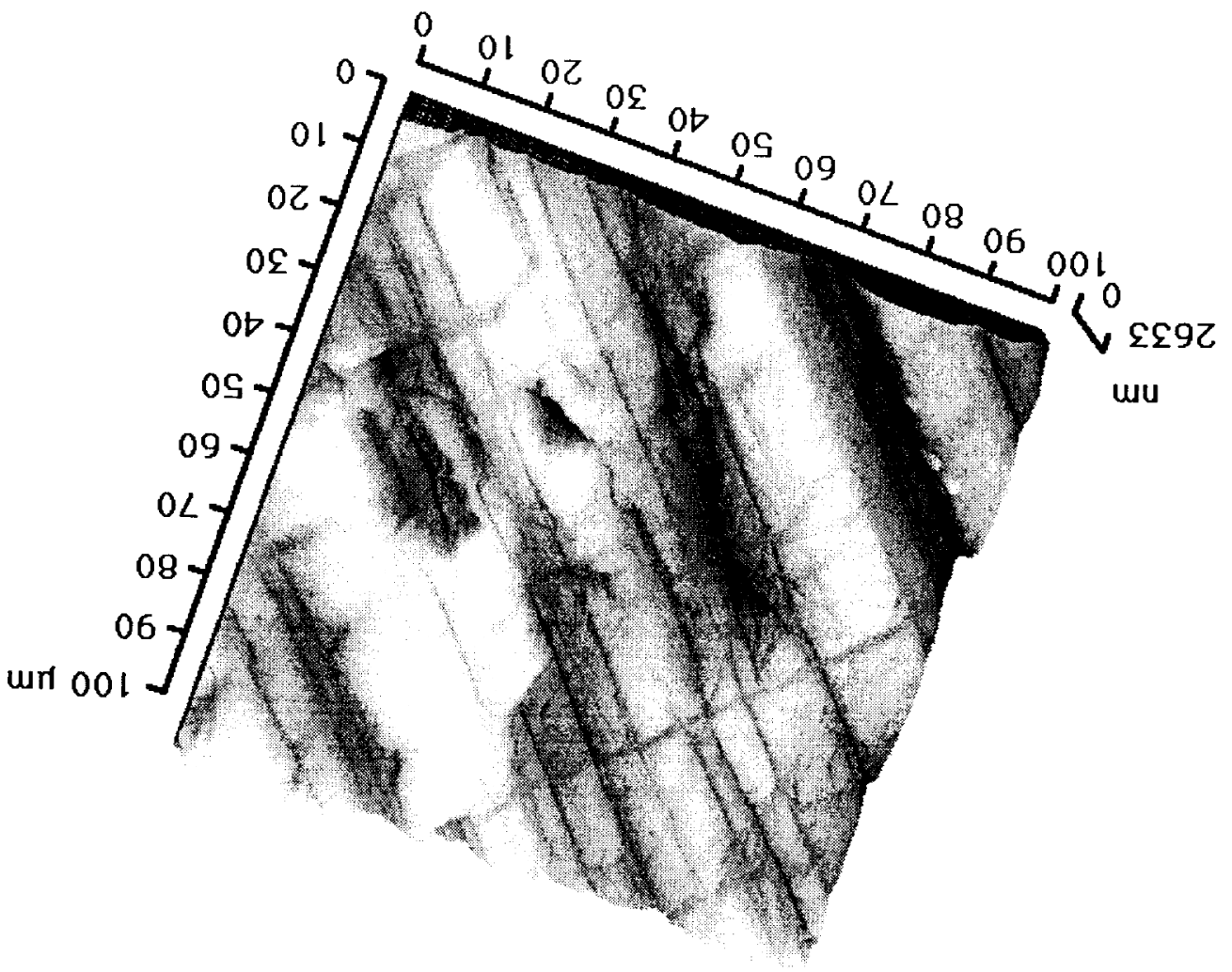




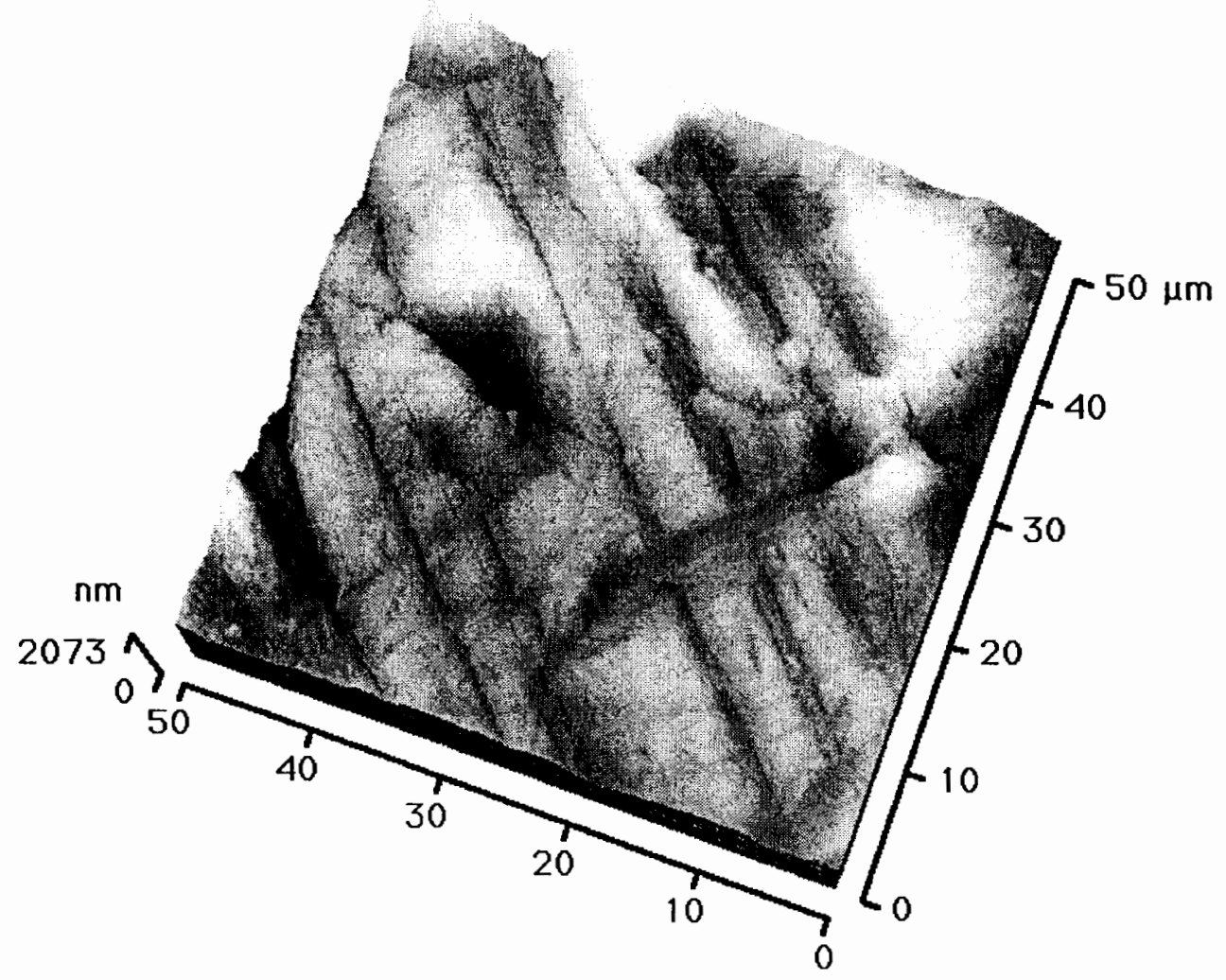

Figure 22: Detail of the lower right region of Figure 21. (file 991122a.002). 


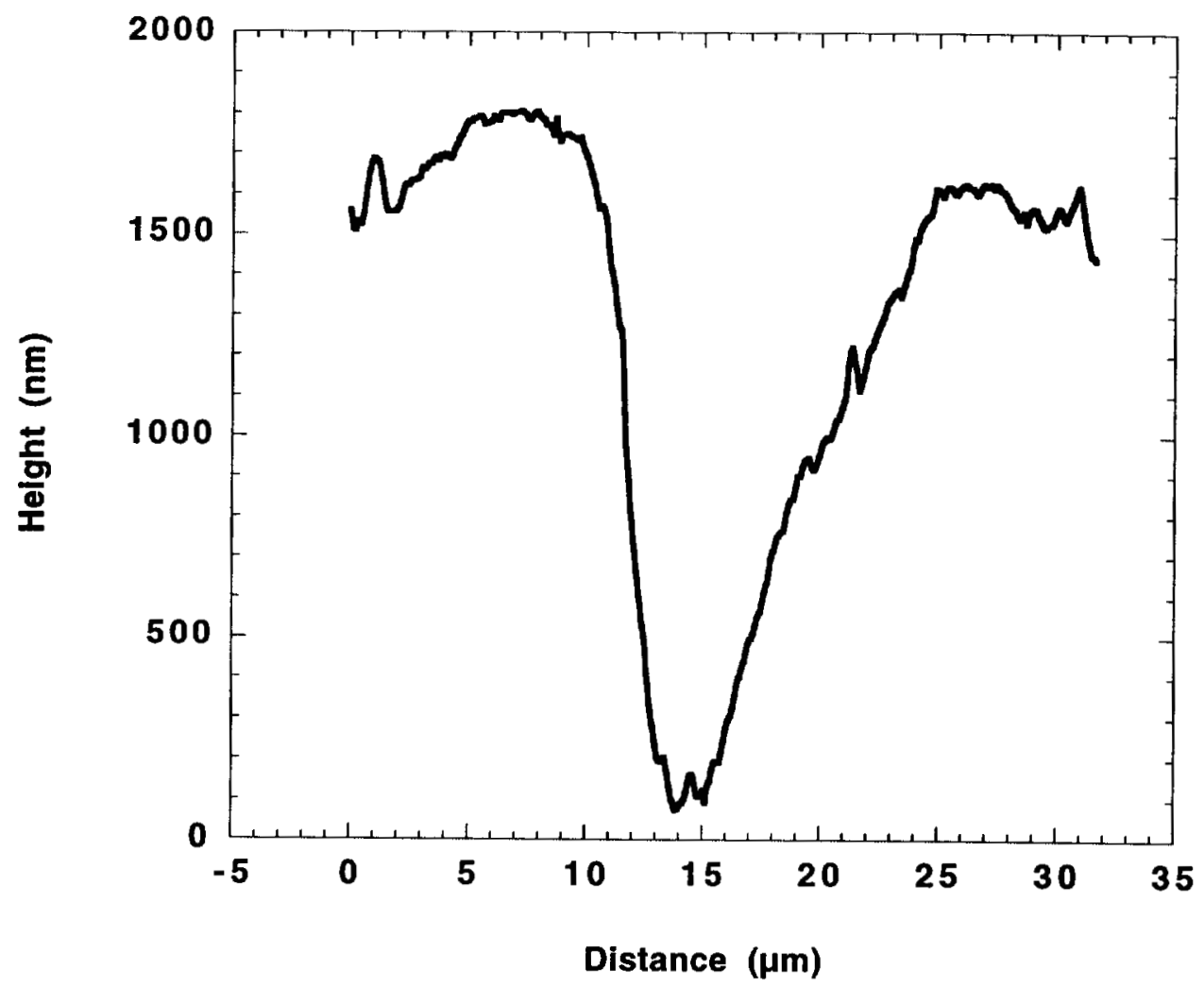

Figure 23: Profile of the depression appearing in the left center region of Figure 22. 


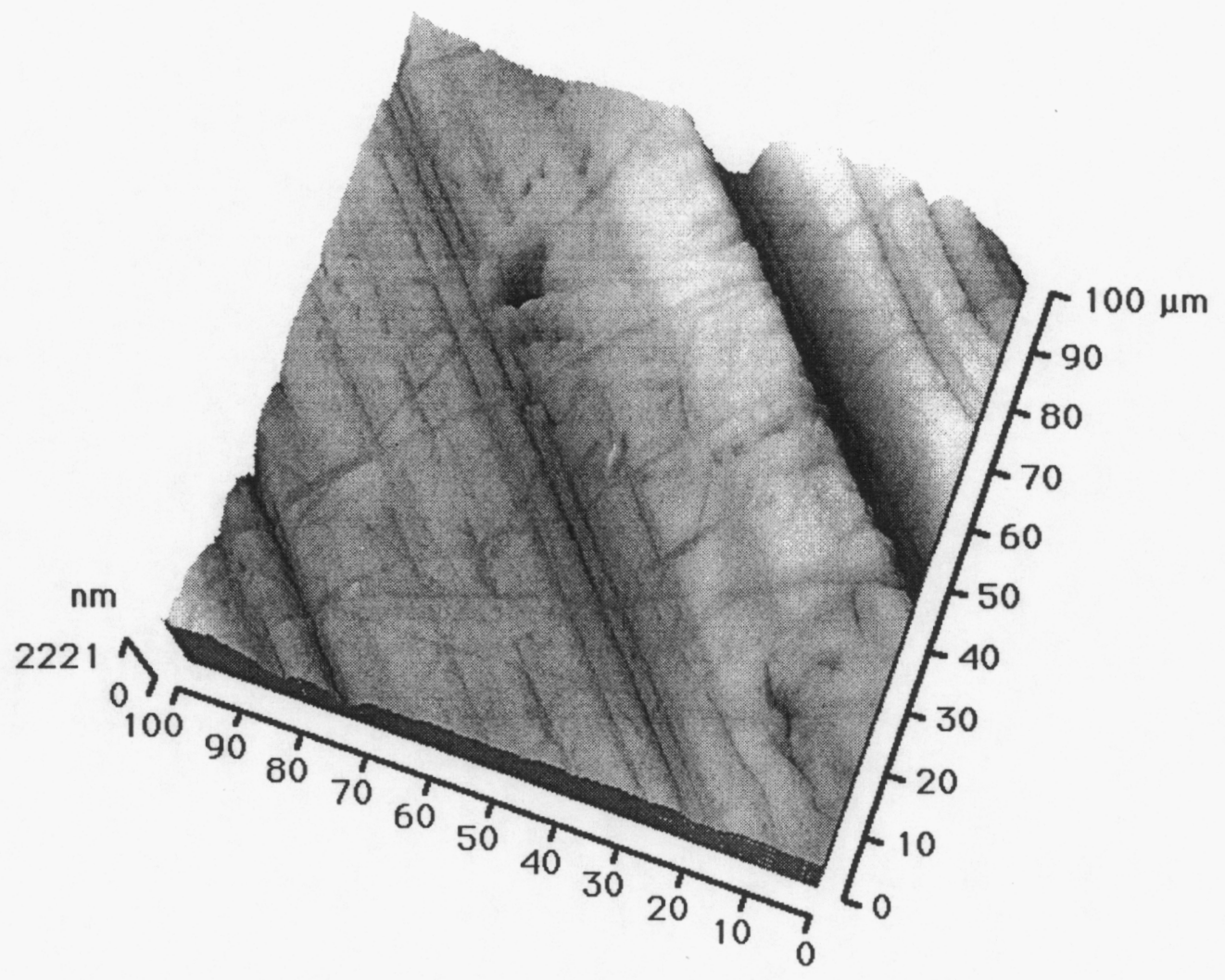

Figure 24: Obverse side of DCA076, exposed to 60C SCW for two years, inside crevice. (file 991122a.003) 


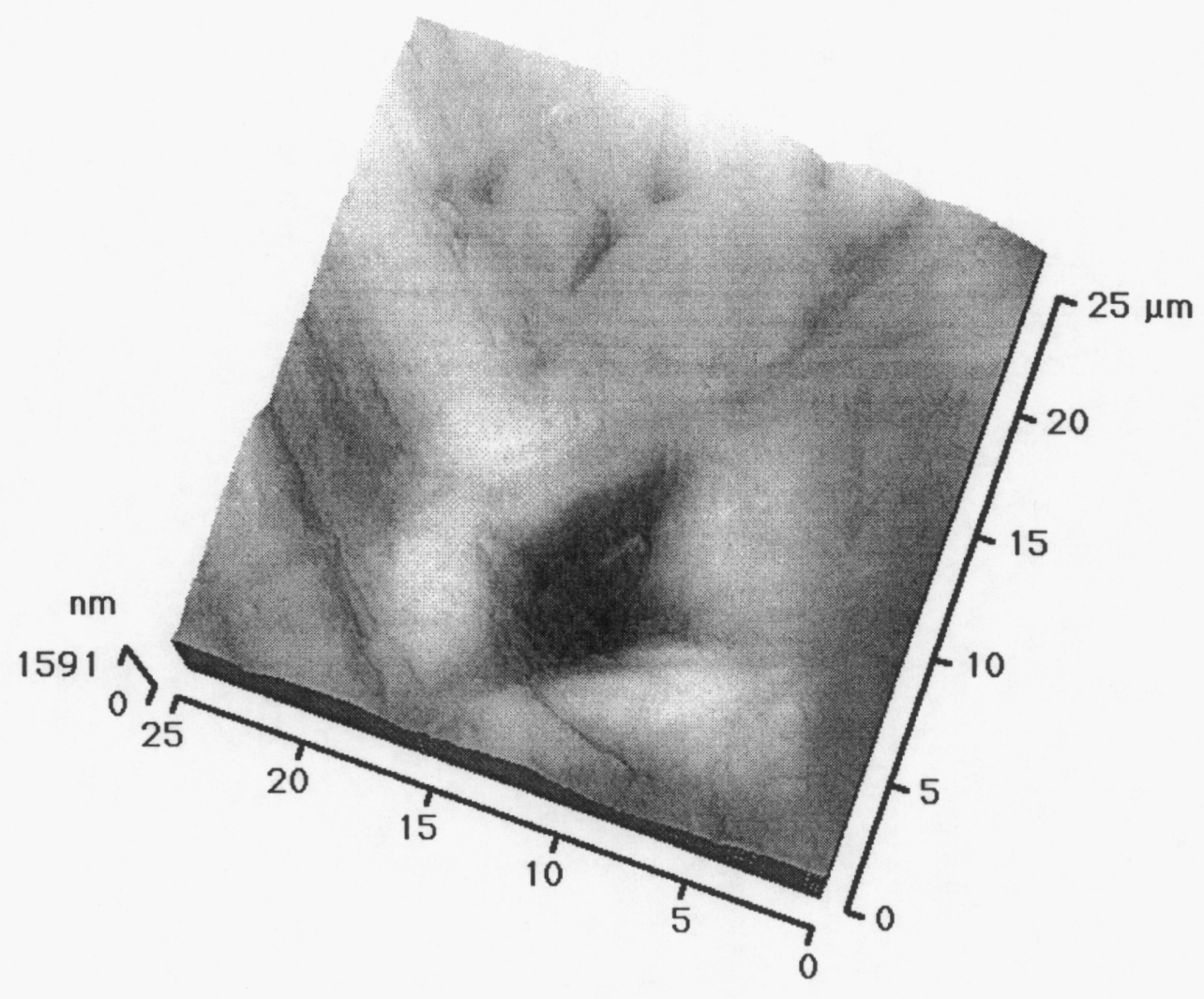

Figure 25: Detail of the depression appearing in the upper left region of Figure 24. (file 991122a.004) 


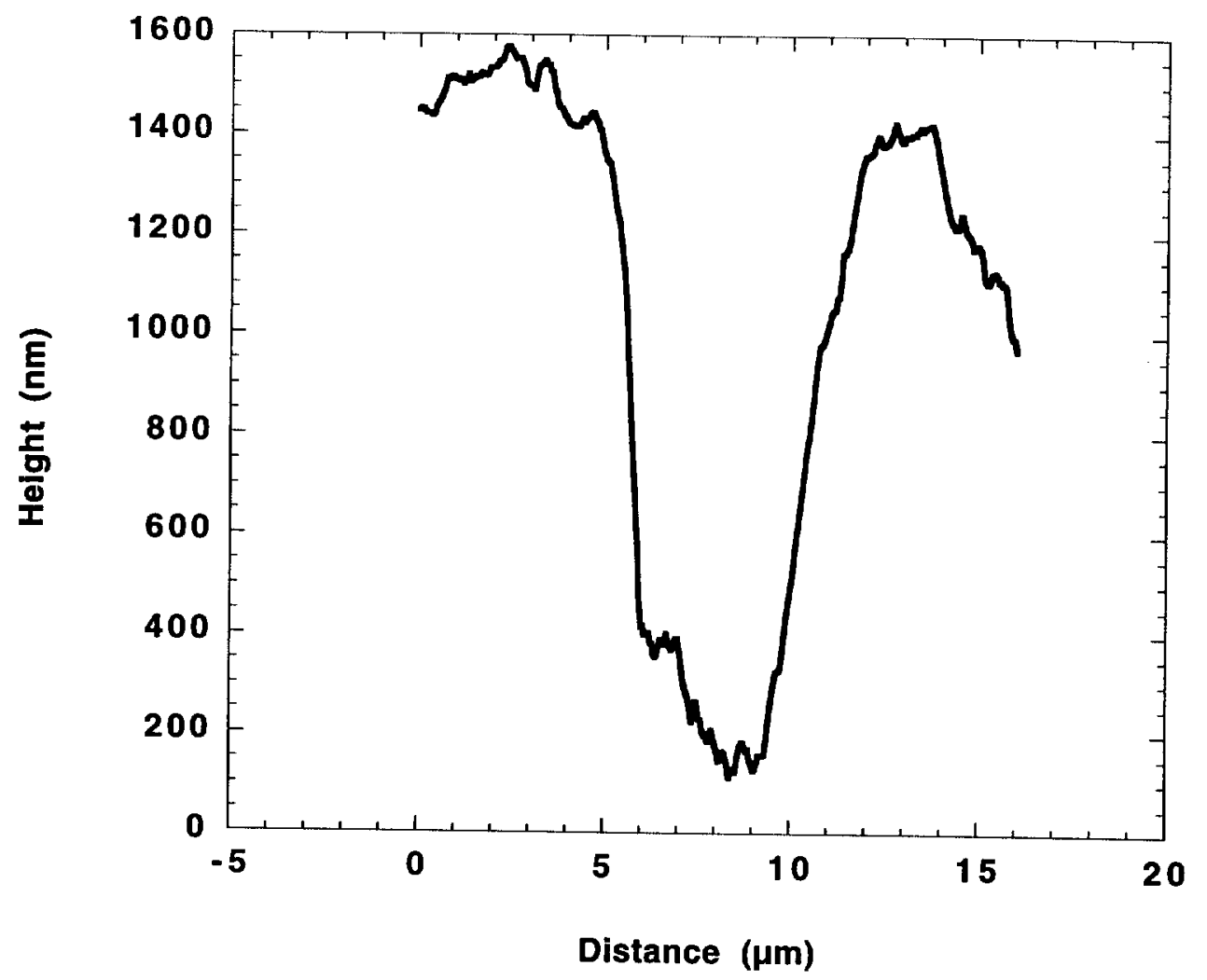

Figure 26: Profile of the prominent depression appearing in Figure 25. 


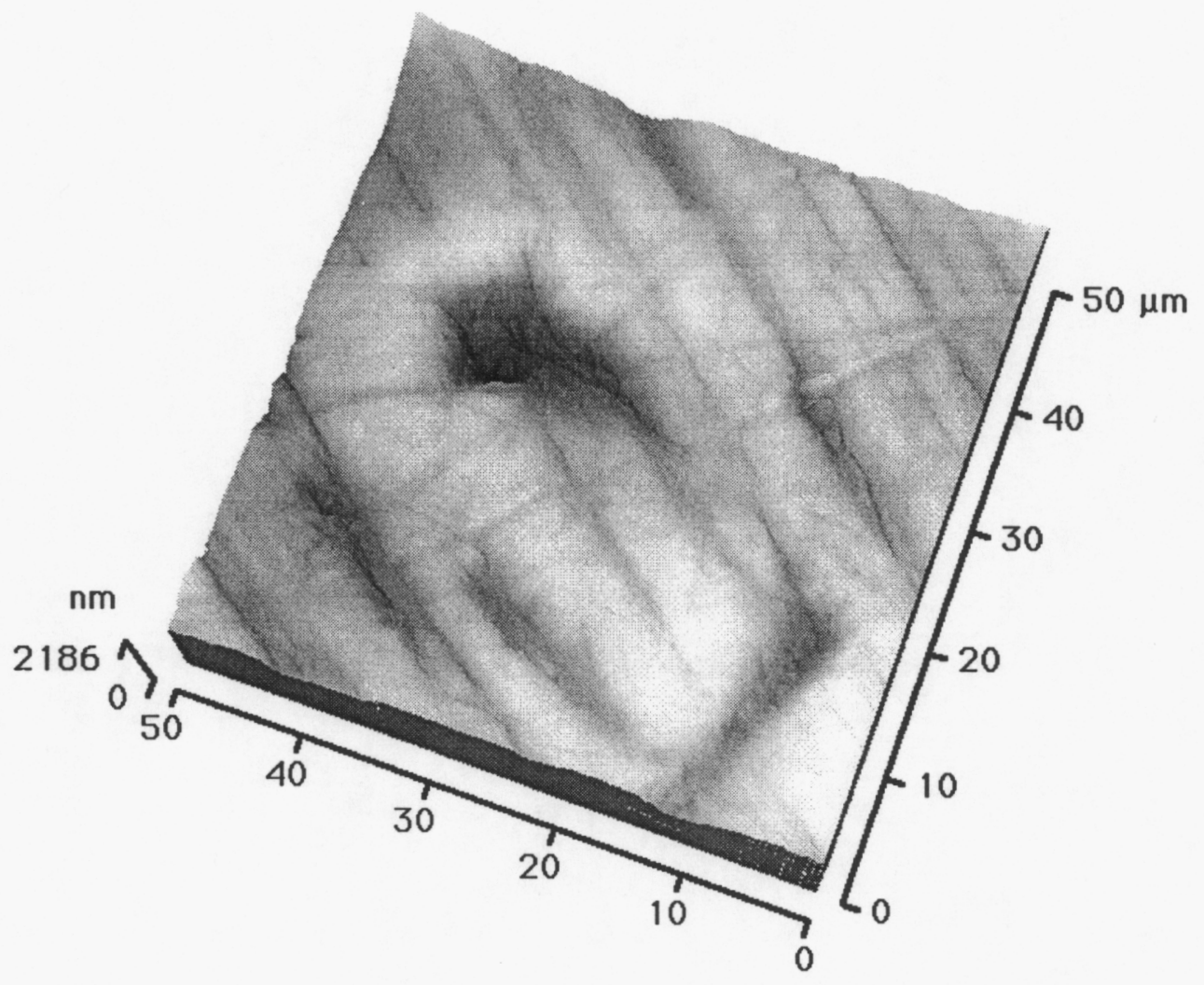

Figure 27: Obverse side of DCA076, exposed to 60C SCW for two years, outside crevice. (fille 991122a.007) 


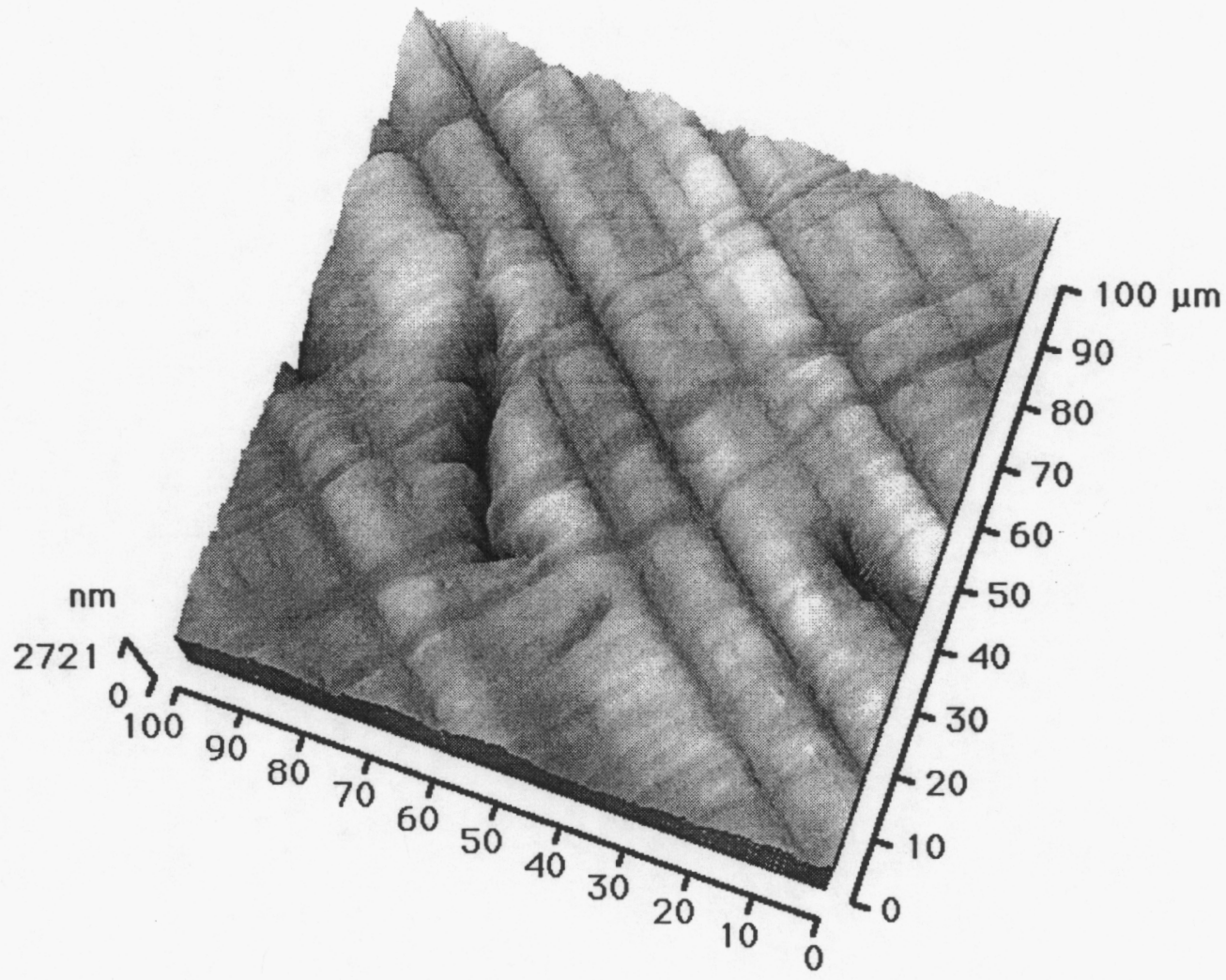

Figure 28: Obverse side of DCA136, exposed to 60C SDW for two years, inside crevice. (file 991123a.002) 


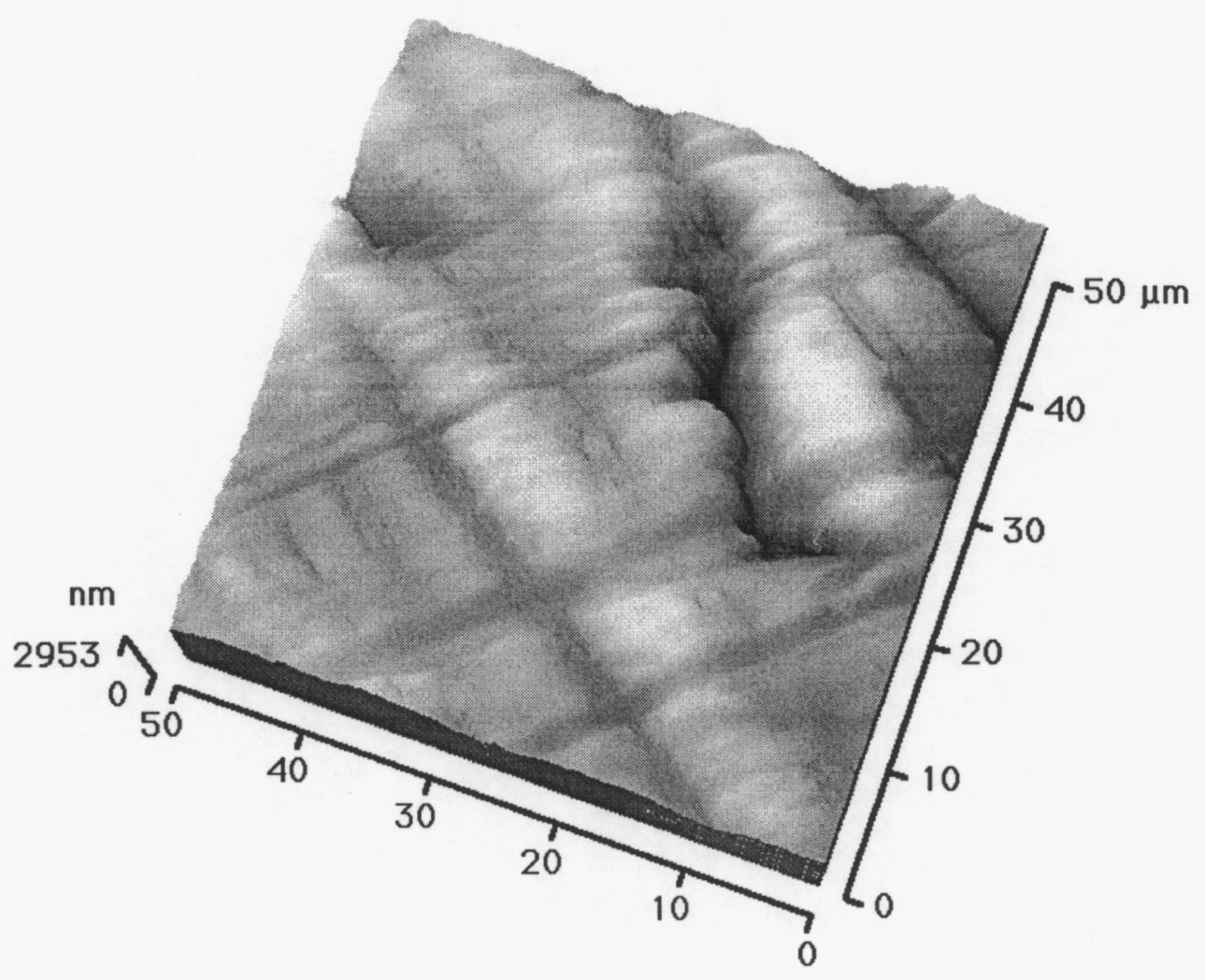

Figure 29: Detail of the left center region of Figure 28. (file 991123a.003) 


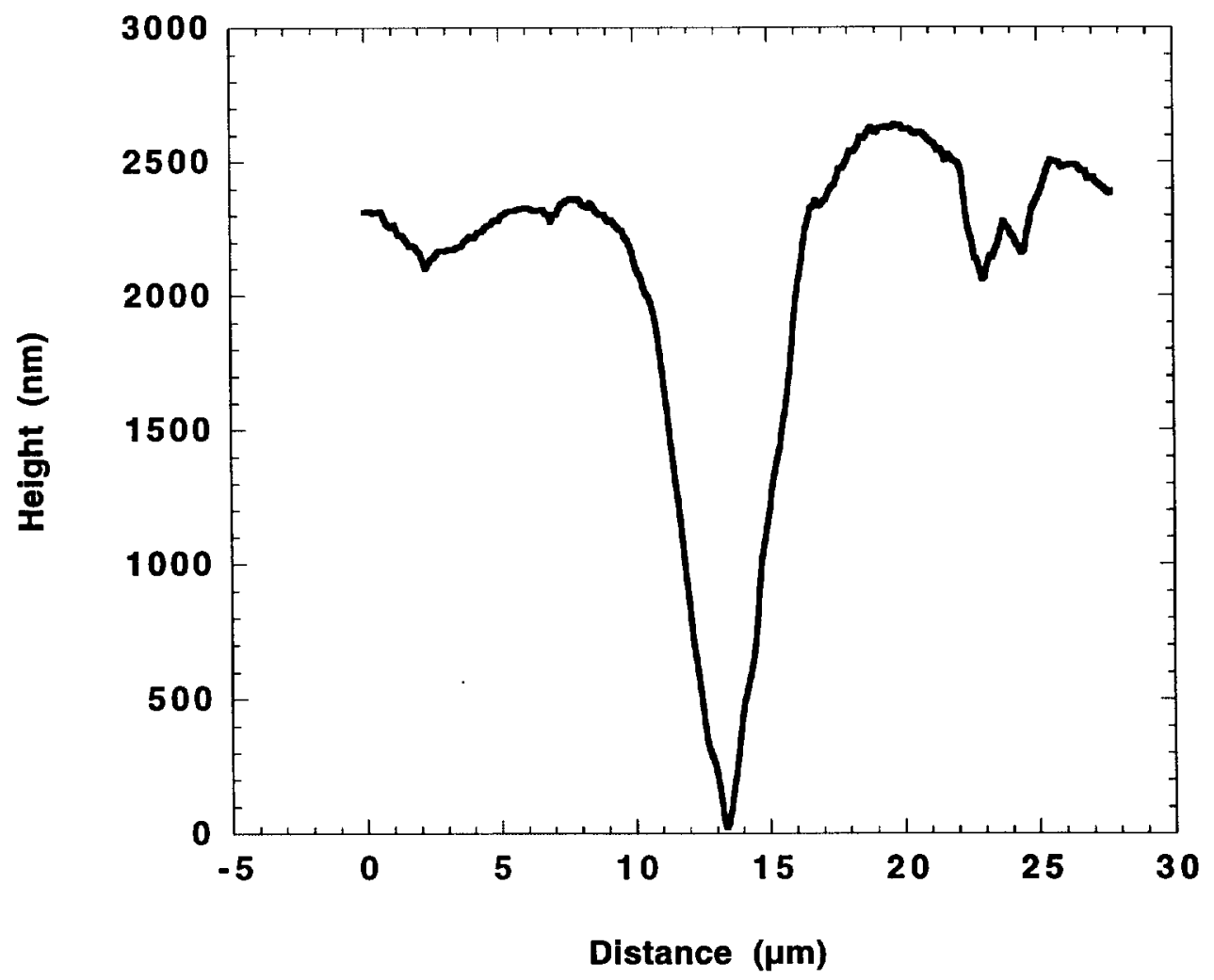

Figure 30: Profile across the prominent depression appearing in Figure 29. 


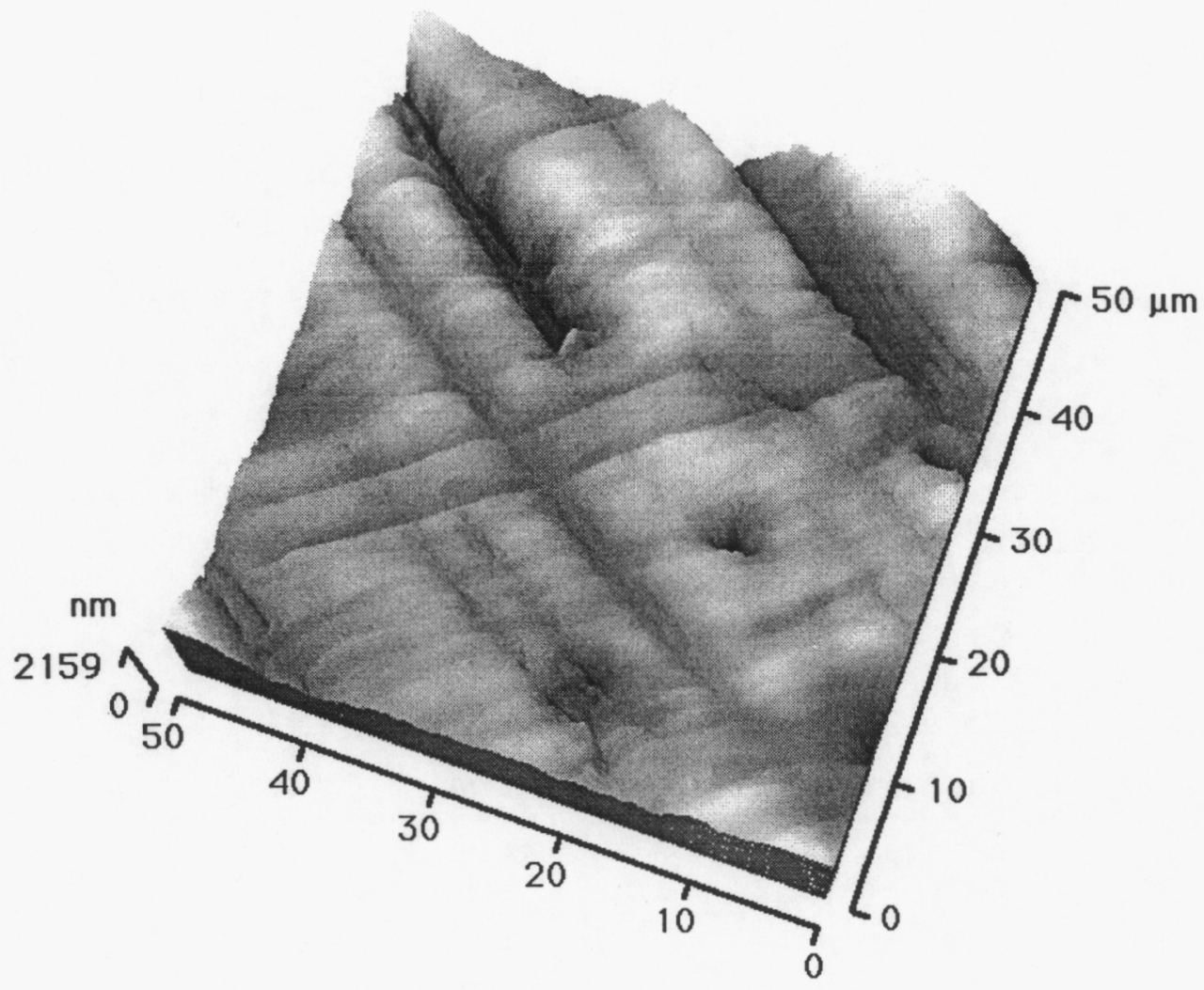

Figure 31: Obverse side of DCA136, exposed to 60C SDW for two years, inside crevice. (file 991123a.005) 


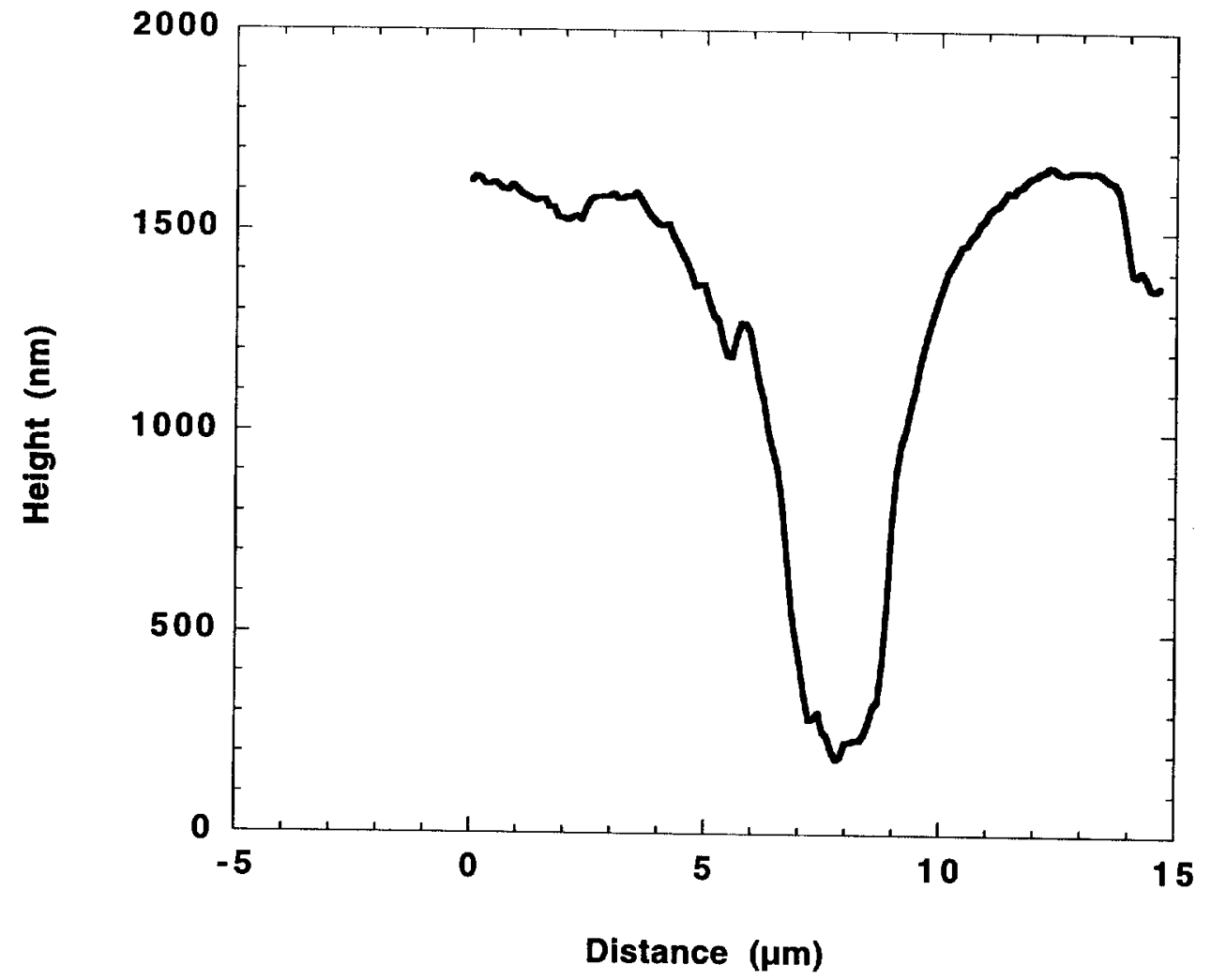

Figure 32: Profile of the narrow depression appearing in the right central region of Figure 31 . 


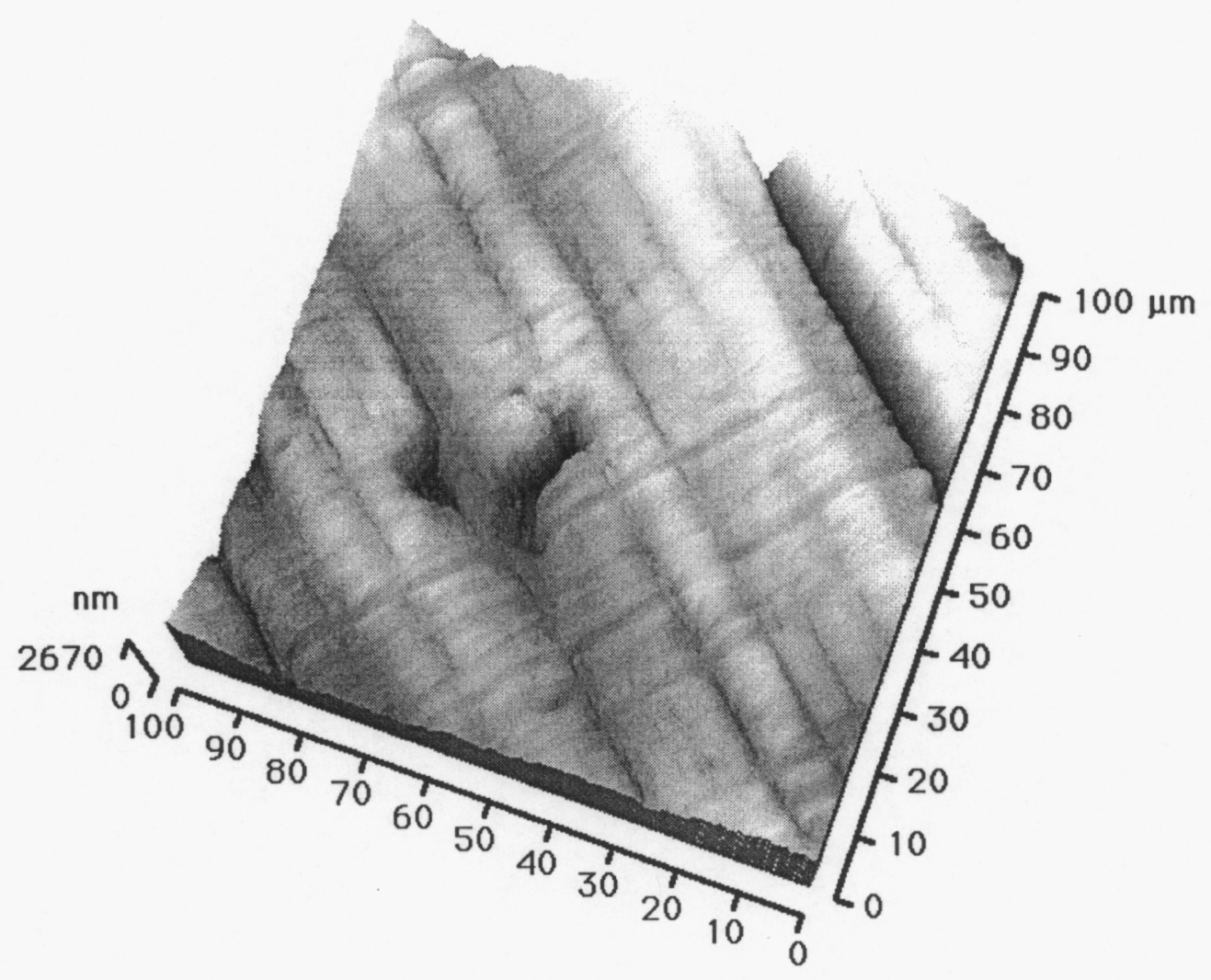

Figure 33: Obverse side of DCA136, exposed to 60C SDW for two years, outside crevice. (file 991123a.006) 


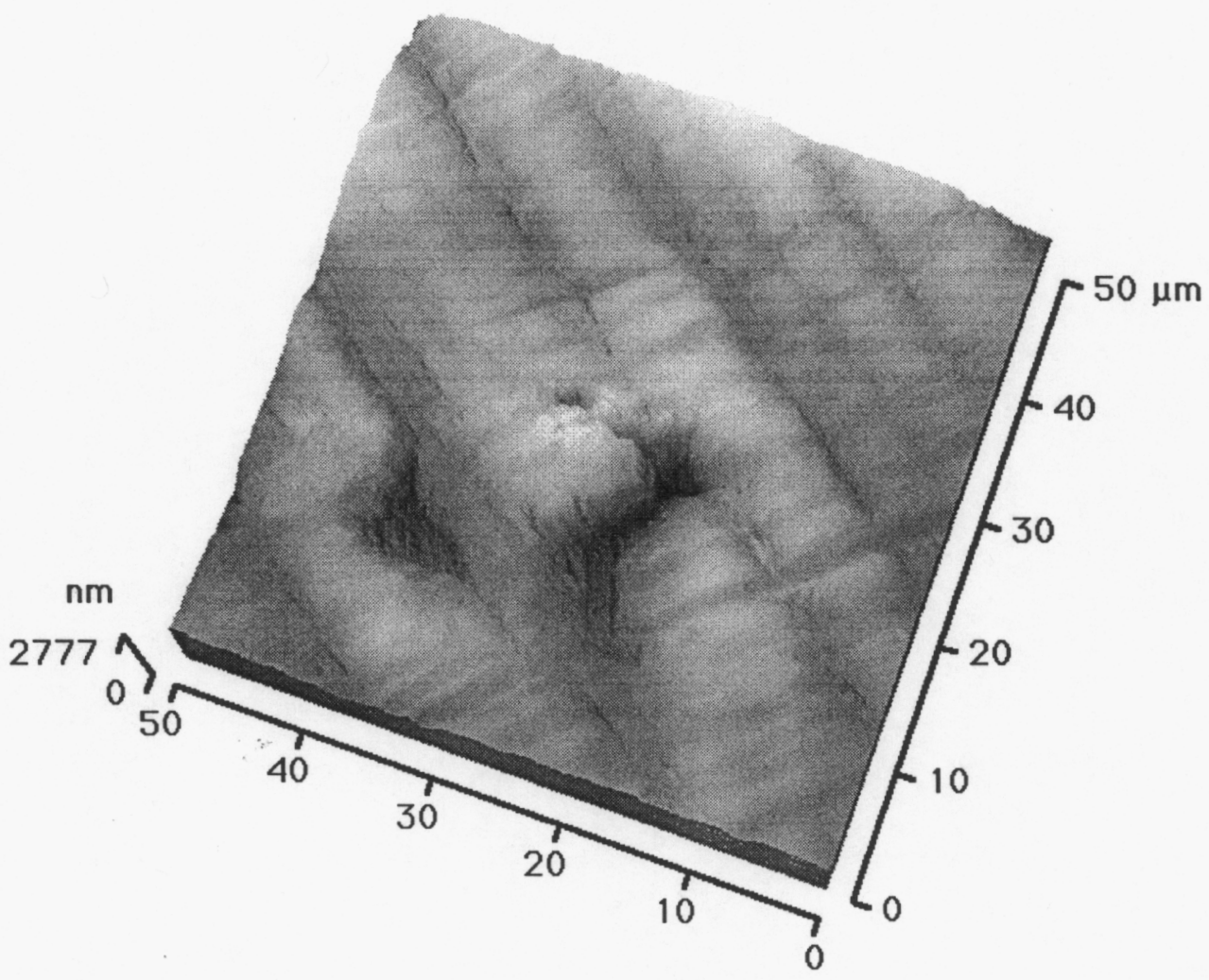

Figure 34: Detail of the lower left region of Figure 33. (file 991123a.007). 


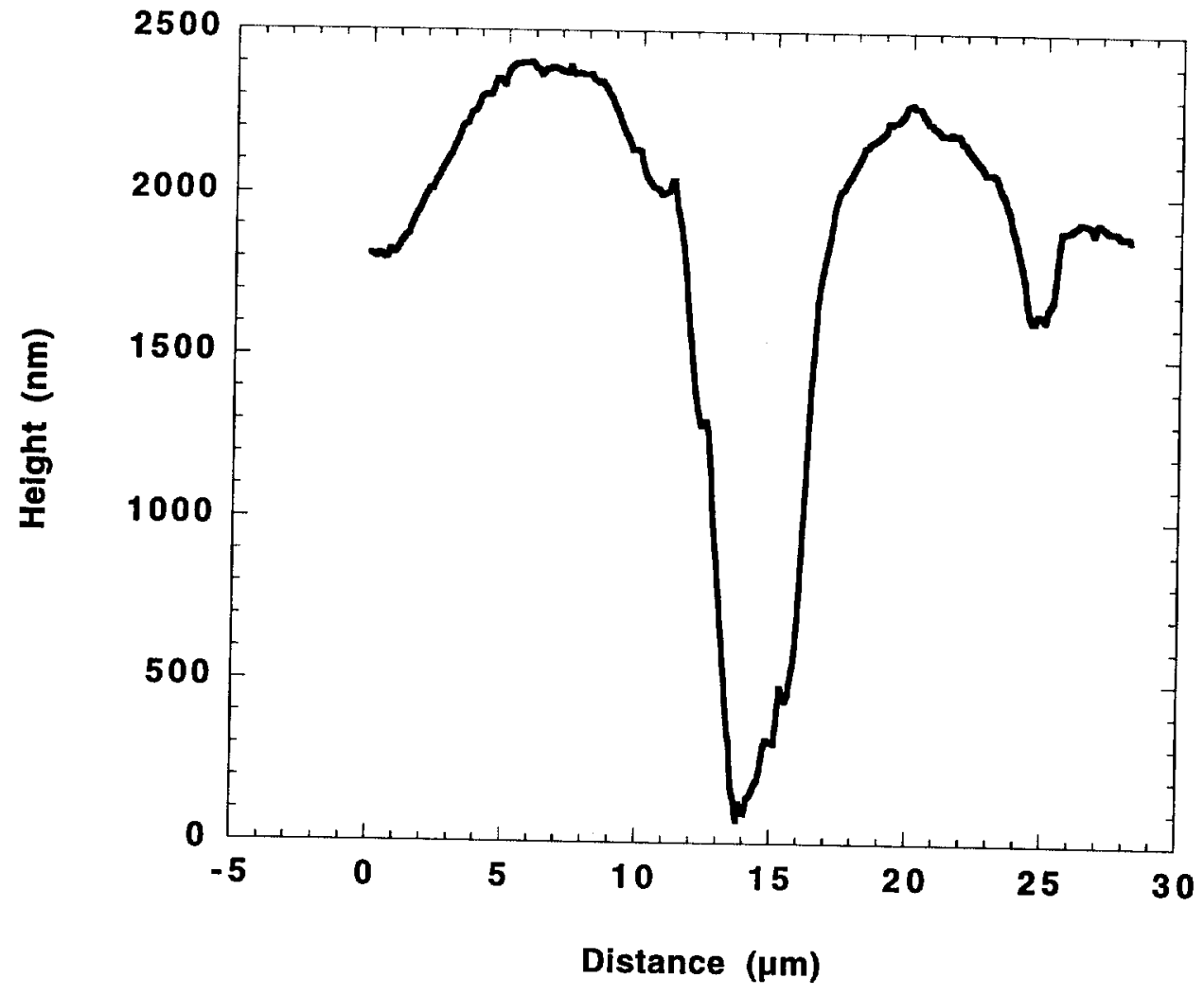

Figure 35: Profile of the upper right depression in central region of Figure 34. 


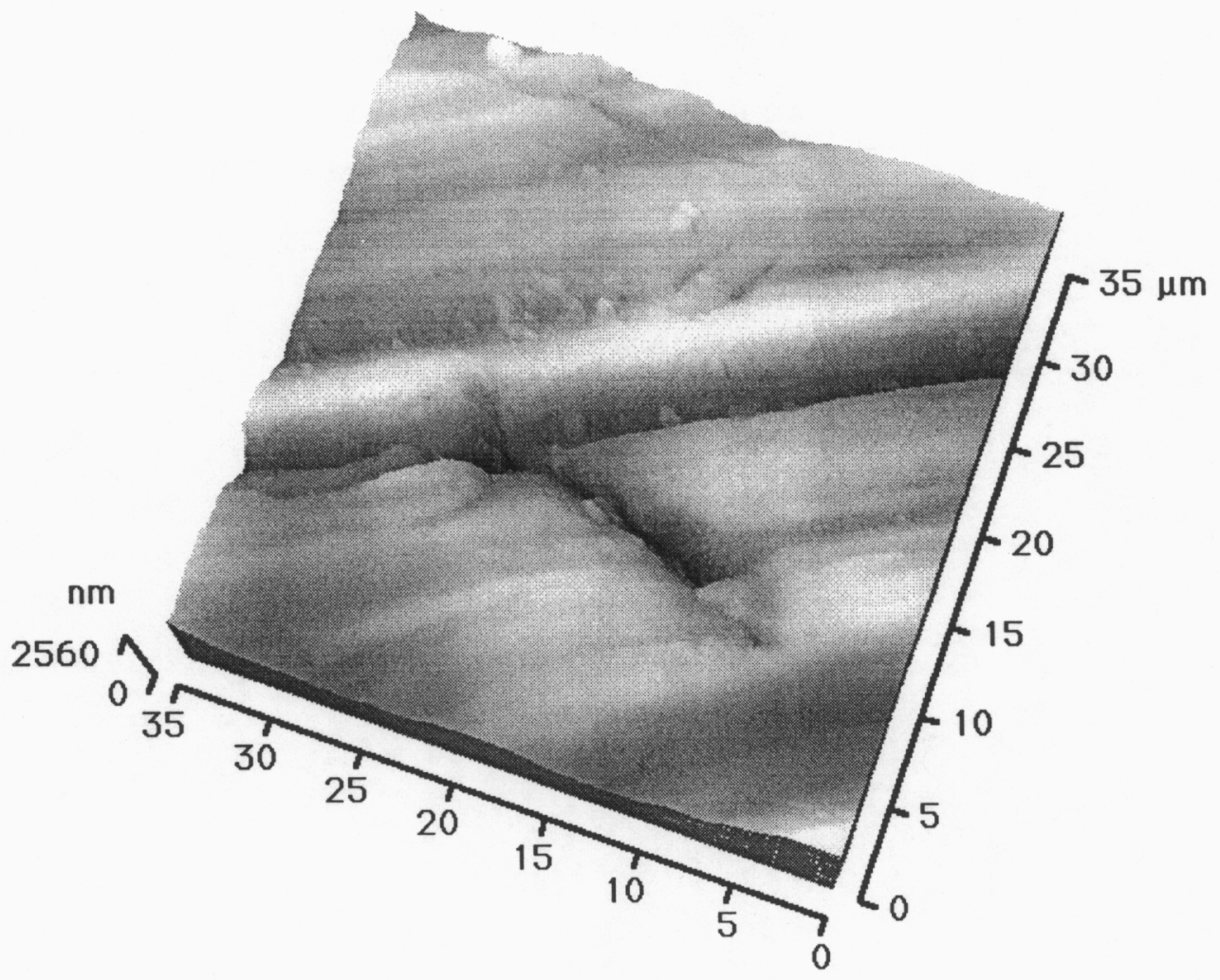

Figure 36: Obverse side of DCA243, an unexposed, control, crevice coupon. (file 991129a.002) 


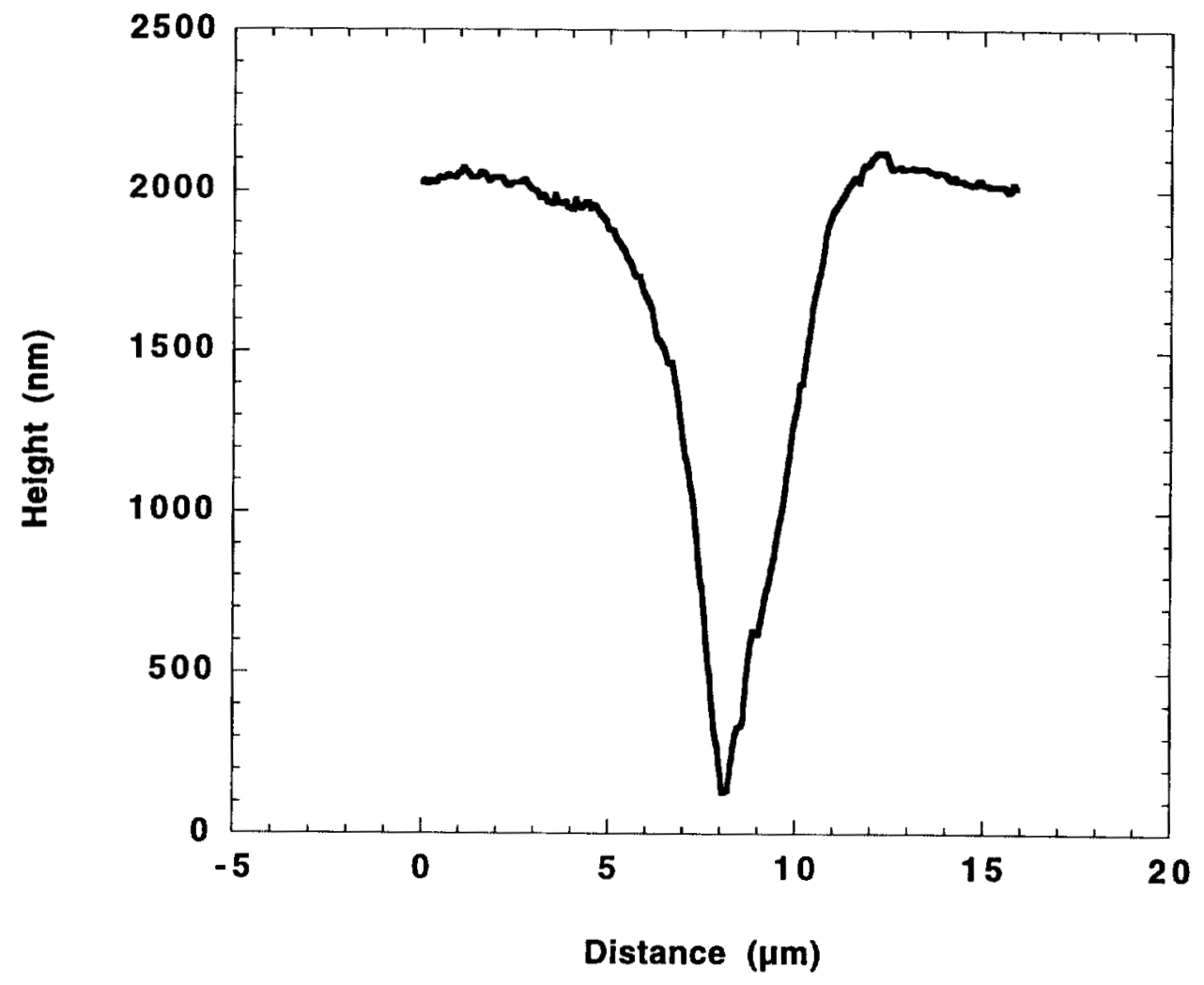

Figure 37: Profile of the prominent depression in the lower right of Figure 36. 


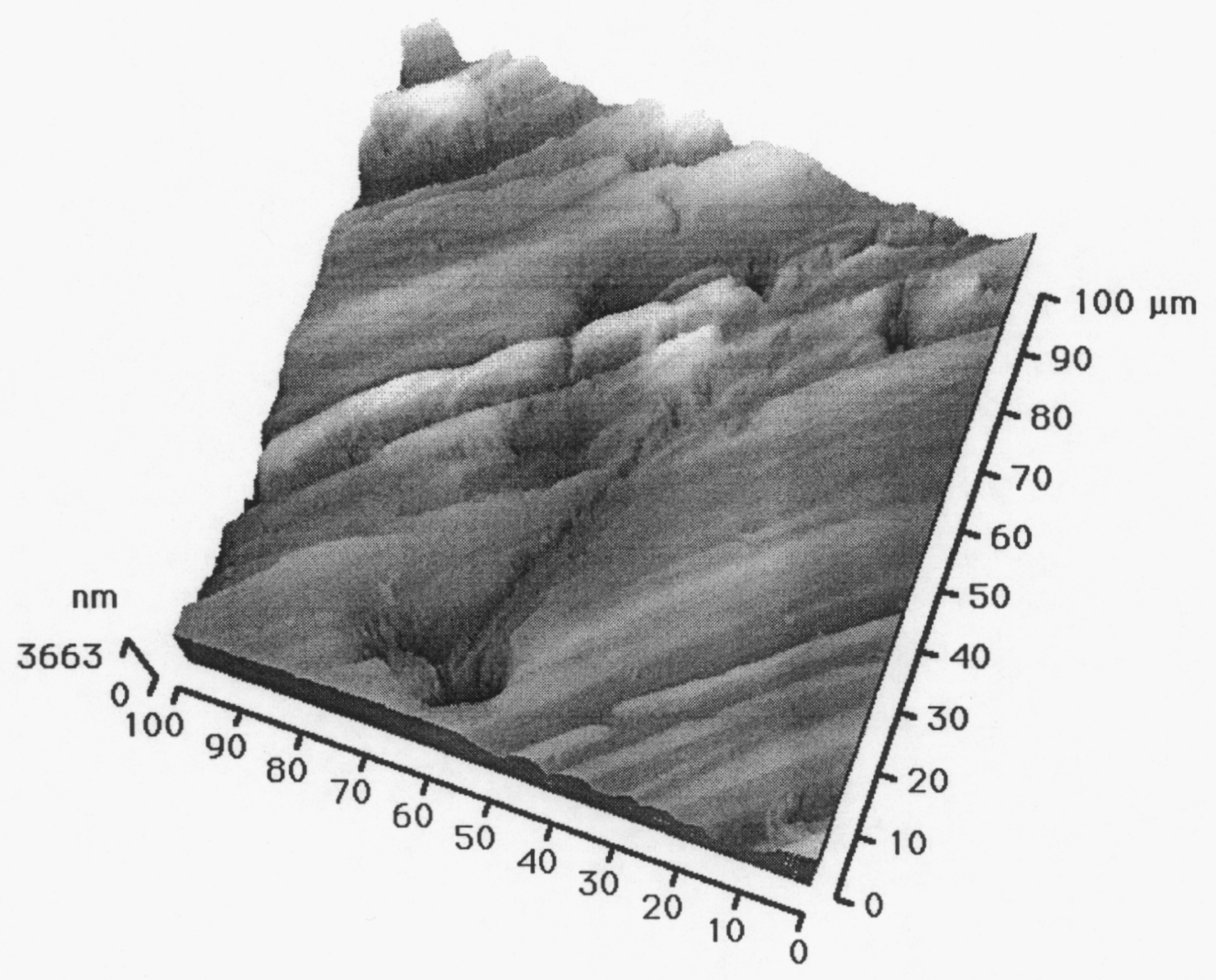

Figure 38: Obverse side of DCA243, an unexposed, control, crevice coupon. (file 991129a.003) 


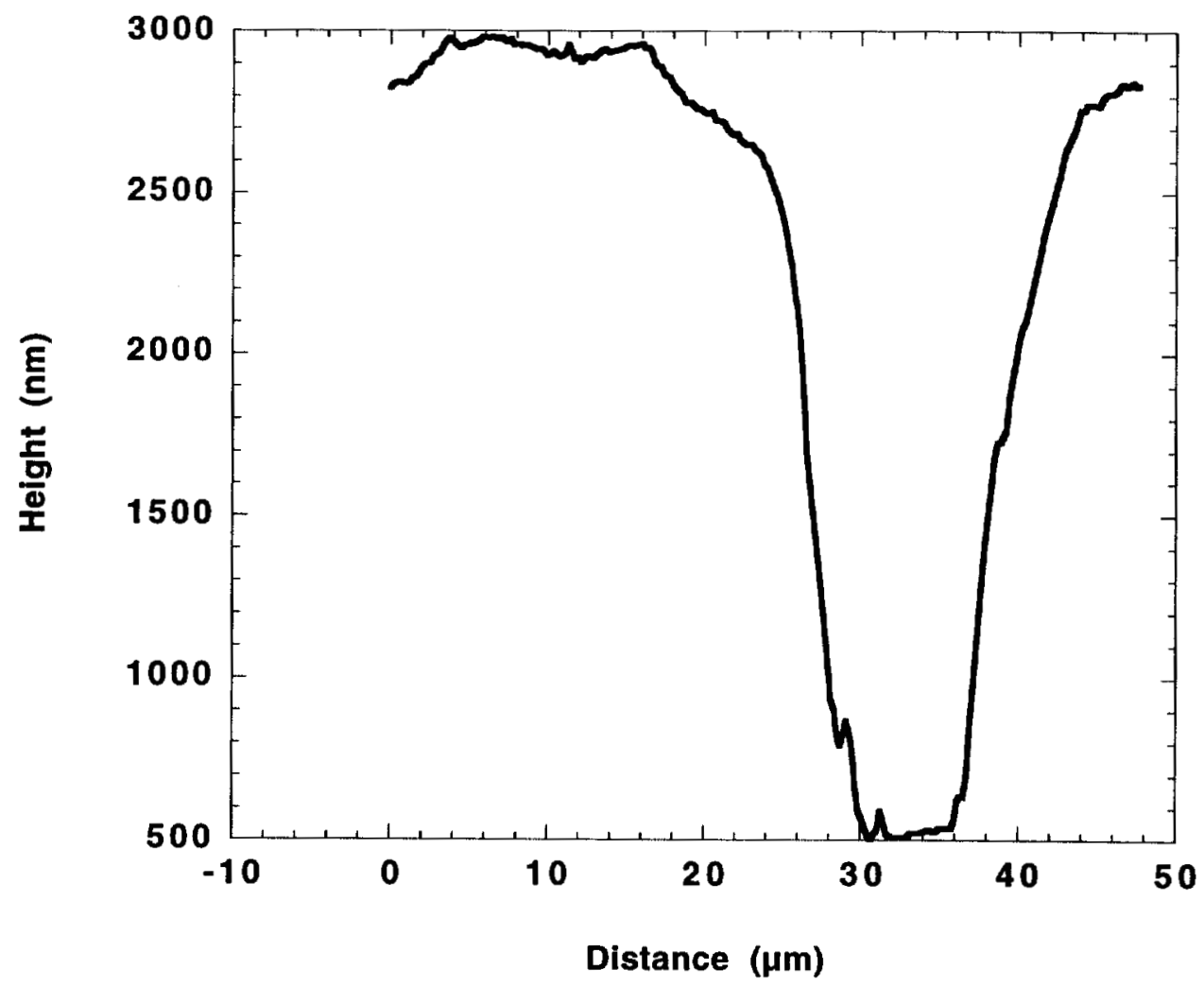

Figure 39: Profile of the depression in the lower portion of Figure 38. 


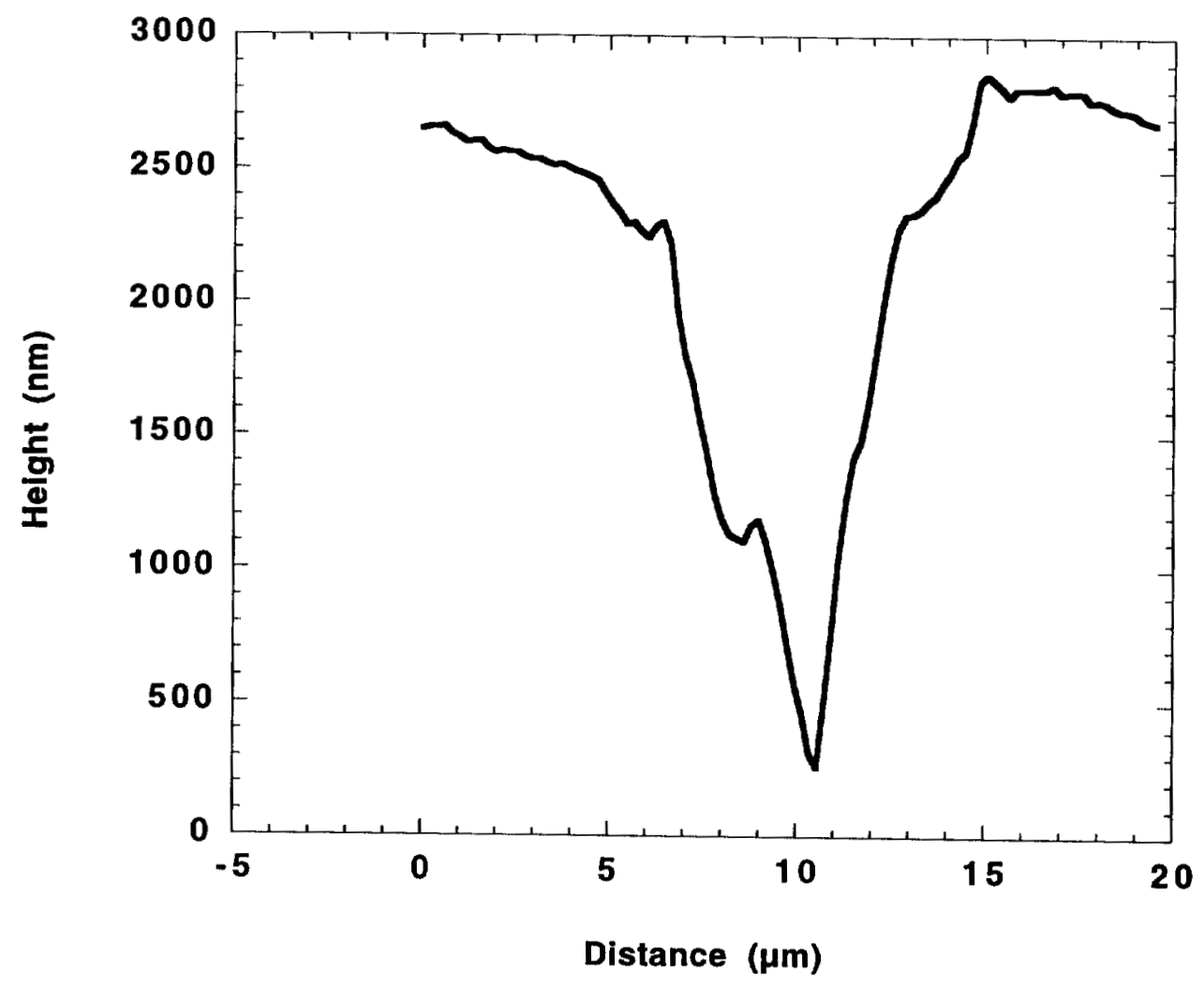

Figure 40: Profile of the depression in the upper central region of Figure 38. 